\title{
A simulated geochemical rover mission to the Taurus-Littrow valley of the Moon
}

\author{
Randy L. Korotev, Larry A. Haskin, and Bradley L. Jolliff \\ Department of Earth and Planetary Sciences and McDonnell Center for the Space Sciences, Washington University, \\ Saint Louis, Missouri
}

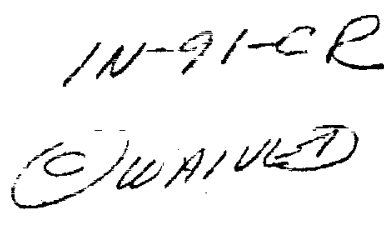

\begin{abstract}
We test the effectiveness of using an alpha backscatter, alpha-proton, X ray spectrometer on a remotely operated rover to analyze soils and provide geologically useful information about the Moon during a simulated mission to a hypothetical site resembling the Apollo 17 landing site. On the mission, 100 soil samples are "analyzed" for major elements at moderate analytical precision (e.g., typical relative sample standard deviation from counting statistics: $\mathrm{Si}[11 \%], \mathrm{Al}[18 \%], \mathrm{Fe}[6 \%], \mathrm{Mg}[20 \%], \mathrm{Ca}[5 \%])$. Simulated compositions of soils are generated by combining compositions of components representing the major lithologies occurring at the site in known proportions. Simulated analyses are generated by degrading the simulated compositions according to the expected analytical precision of the analyzer. Compositions obtained from the simulated analyses are modeled by least squares mass balance as mixtures of the components, and the relative proportions of those components as predicted by the model are compared with the actual proportions used to generate the simulated composition. Boundary conditions of the modeling exercise are that all important lithologic components of the regolith are known and are represented by model components, and that the compositions of these components are well known. The effect of having the capability of determining one incompatible element at moderate precision ( $25 \%$ ) is compared with the effect of the lack of this capability. We discuss likely limitations and ambiguities that would be encountered, but conclude that much of our knowledge about the Apollo 17 site (based on the return samples) regarding the distribution and relative abundances of lithologies in the regolith could be obtained. This success requires, however, that at least one incompatible element be determined.
\end{abstract}

\section{Introduction}

Future missions to the Moon and other planets will undoubtedly include rovers, i.e., unmanned mobile devices for making observations and measurements. A desirable instrument aboard any such rover is a geochemical analyzer capable of determining elemental compositions of rocks and soils. There is little experience in the scientific community with interpretation of data from such an instrument because portable geochemical analyzers are not used in terrestrial geologic exploration, and missions that have carried such devices to other planets have usually made only one or a few measurements [e.g., Turkevitch et al., 1968; Clark et al., 1982; Surkov et al., 1986]. This paper deals with the interpretation of imprecise elemental compositions obtained remotely on a large number of samples taken at different locations.

We consider a simulated rover mission to the TaurusLittrow valley of the Moon, the site of the Apollo 17 mission. It is one of the most geologically diverse of the Apollo sites, and the relationship between the site geology and the regolith composition is reasonably well understood [Rhodes et al., 1974; Korotev and Kremser, 1992]. Different areas of the site are dominated by different rocks types and, as a consequence, soil compositions are highly variable from place to place. Building on what we know about the rock types and

Copyright 1995 by the American Geophysical Union.

Paper number $95 \mathrm{JE} 01670$.

$0148-0227 / 95 / 95 \mathrm{JE}-01670 \$ 05.00$ their compositions, our simulated mission considers what new things we might learn if we were to extend the traverse range beyond the area covered by the astronauts (e.g., into the Sculptured Hills, higher onto the massifs, out into the Serenitatis basin) using a state-of-the-art, but simple, chemical analyzer. Indirectly, however, we test whether our rover would discover the kinds of things we already know about the site.

We assume the capability to examine rocks visually and determine their chemical compositions, albeit not as precisely as in the laboratory. Our simulated geochemical rover mission, however, focuses on regolith fines for several reasons. (1) Overall, soils are omnipresent, and their compositions reflect site geology broadly and generally and thus provide unique constraints on geologic interpretations. (2) Subjective selection of rocks for analysis will almost certainly miss some volumetrically important components of the regolith, the presence of which might be inferred from soil analyses (e.g., the Apollo 17 pyroclastics). (3) Soil compositions provide better indications of the relative abundance of subsurface rock types than the analyses of any reasonable number of rocks lying on the surface. (4) Lateral transport of regolith is relatively minor, but soil compositions will vary along a traverse. Thus a map of lithologic components of the regolith, as inferred from soil compositions, helps define the provinces of local rock types, this being information difficult to obtain by other means. (5) We assume that it will be operationally easier to obtain an accurate and representative analysis of a fines sample (i.e., <1-mm material) than of a rock sample. This assumption is based mostly on the greater degree of reproducibility of the sample surface and the sample-to-instrument geo- 
metry expected with a sample of fines. (6) In situ analysis of large rocks requires that the rover remain stationary during analysis. It should be logistically straightforward, however, to recover a soil sample and analyze it on board while traveling to the next destination. (7) Improved understanding of pyroclastic deposits is an important lunar science objective, and any mission involving the study of such deposits must face the challenge of interpreting data for mixtures of ash and comminuted rock. (8) Any resource utilization on the lunar surface will primarily involve the regolith, rather than large rocks, so characterization of soil is essential. (9) The techniques discussed here for interpreting compositional data for regolith fines, as well as many of the conclusions reached below, are also applicable to interpretation of results from orbiting geochemical missions for which only the regolith is observed; they are also applicable to surface analysis of Mars and asteroids. Thus the main subject of this paper is how to interpret, in a geologically reasonable way, imprecise (by laboratory standards) compositional data for regolith fines obtained by a mobile geochemical analyzer.

Because our simulated mission returns to the TaurusLittrow site, an advantageous boundary condition on interpretations is our prior knowledge of what rock types occur at the site and what their chemical compositions are. In a subsequent paper, we will consider the more challenging question of what we might leam from a rover mission to an unexplored lunar site.

\section{Mission Strategy}

\subsection{Mission Goals}

We would regard our lunar rover mission to the Apollo 17 site a success if it could determine at least the first-order relationships that we have determined from the manned mission. These are the following: (1) the valley floor consists primarily of high-Ti mare basalt, (2) the South Massif consists of noritic impact-melt breccia and some type of feldspathic lithologies in subequal abundance with little contamination by mare material, and (3) the North Massif soils are similar in composition to those of the South Massif, except that feldspathic components are more abundant than the melt-breccia component and mare basalt is more abundant. Because the site is at a mare-highlands boundary, it would be useful if the rover could determine (4) the relative proportions of mare and highlands lithologies in each soil sample so we could assess the extent of mixing. The rover mission would be particularly successful if (5) the "orange-glass soil" found at station 4 could be discovered and recognized as a pyroclastic deposit and if (6) the plutonic norites and troctolites found at the North Massif were recognized. The mission would be extremely successful if it recognized that, in addition to the abundant high-Ti mare basalt, (7) much less abundant very low $\mathrm{Ti}$ (VLT) basalt was present in the regolith, and that (8) KREEP basalt occurred at the site.

\subsection{Sampling Strategy}

Based on our experience with samples studied in the laboratory and on some initial results of the present exercise, we can show that chances of mission success increase with increasing number of sample analyses, that for soils a greater number of low-precision analyses is preferable to a few highprecision analyses, and that 100 soil analyses is a reasonable number for a site as complicated as the Taurus-Littrow valley. (On the Apollo 17 mission, 68 bulk soil samples and six regolith cores were collected.) This means that analysis time for a routine sample will have to be short, probably not more than an hour, and that uncertainties in element concentrations will be greater than ideal.

\subsection{The $\alpha-p-x$ Spectrometer}

The primary geochemical instrument on our rover is the $\alpha-\mathrm{p}-\mathrm{x}$ (alpha-proton-X ray) spectrometer described by Economou and Turkevich [1976, 1992]. This instrument is capable of determining the concentrations of all major elements, i.e., those present in concentrations greater than about $1 \%$. The instrument also appears to be capable of determining some elements at low precision that are minor elements on the Moon, the most promising of which for the purposes described here are $\mathrm{Na}, \mathrm{K}, \mathrm{P}$, and $\mathrm{Cr}$. In our simulated mission, we will consider only $\mathrm{O}, \mathrm{Si}, \mathrm{Ti}, \mathrm{Fe}, \mathrm{Mg}, \mathrm{Ca}, \mathrm{Na}$, and $\mathrm{K}$ because these are the elements for which Economou and Turkevich [1992] provide analytical uncertainties. Instead of modeling metal oxides [e.g., Korotev and Kremser, 1992], we treat oxygen explicitly because it is determined directly by the $\alpha-p-x$ spectrometer, and more precisely than are many of the metallic elements.

\subsection{Incompatible Elements}

A challenge for any geochemical rover mission will be to obtain data for some trace and minor elements, in particular, the geochemically incompatible elements, or IEs. The only IEs for which the $\alpha \cdot \mathrm{p}-\mathrm{x}$ instrument is likely to provide any useful data are $K$ and $P$, and then only with very long analysis times or when those elements happen to be in atypically high concentrations. A fascinating property of soils and most other polymict lunar samples in which the concentrations of IEs are high (particularly, the incompatible trace elements) is that relative proportions of IEs are similar, i.e., ratios of any two IEs are usually the same within a factor of 2 or less. Thus, from the concentration of one IE such as $\mathrm{K}, \mathrm{P}, \mathrm{Y}, \mathrm{Zr}, \mathrm{Ce}$, or $\mathrm{Th}$, the concentrations of others can be estimated well [Haskin and Warren, 1991, Table 8.2]. The constancy of IE ratios among IE-rich lunar samples is taken to indicate that there is one dominant carrier of IEs, designated KREEP, and that KREEP is, or is related to, the residuum from a global magma ocean [Warren and Wasson, 1979a]. Rocks with high IE or KREEP abundances occur primarily in two forms, as igneous rocks in the form of KREEP basalt (at Apollos 15 and 17) and, more commonly, as impact-melt breccias of noritic composition (at most Apollo sites). Thus the ability to determine at least one "KREEP element" is an important goal in the design of any lunar geochemical rover. For our simulated rover mission, however, we employ an ideal, hypothetical instrument that can determine the concentration of Th with a precision of $25 \%$ (one standard deviation). We choose Th because of the community's experience with data obtained for this element remotely [Metzger et al., 1981]. Our model results would be the same for any other IE determined with the same precision. In section 6 , we consider the effects of not having the capability to determine IEs.

\section{Method}

In this and the following sections we first describe our proposed technique of interpreting compositional data obtained 
remotely for lunar soils, namely, by modeling soil compositions as mixtures of lithologic components. We define and describe the model components. We then show that our modeling technique is effective when used with precise laboratory data. We describe our procedure for generating simulated, low-precision analyses of idealized mixtures or actual soil compositions. Finally, we demonstrate the utility of the model for obtaining information on site geology from the simulated low-precision analyses.

\subsection{Identifying Probable Lithologic Components of a Soil}

One objective of compositional studies of soils has been to determine, in conjunction with data obtained on rocks, the relative proportions of the various constituent lithologies and how the variation in those proportions relates to, and provides information about, the site geology. The constituent rock types cannot usually be identified simply by considering normative mineral proportions. For example, mature soils from the Apollo 16 site are all very similar in composition, with $26-27 \% \mathrm{Al}_{2} \mathrm{O}_{3}$. The normative abundance of plagioclase is 78-81 vol \%, which corresponds to noritic anorthosite [Stoffler et al., 1980] (as does much of the lunar highlands surface). However, noritic anorthosite rocks with $26-27 \%$ $\mathrm{Al}_{2} \mathrm{O}_{3}$ are not common in the Apollo 16 collection. The two most common rock types are plutonic anorthosite $(33-35 \%$ $\left.\mathrm{Al}_{2} \mathrm{O}_{3}\right)$ and noritic $\left(17-22 \% \quad \mathrm{Al}_{2} \mathrm{O}_{3}\right)$ impact-melt breccias. These two rock types are not related to each other by any simple igneous process. Thus, resolving the composition of the soil into its normative mineralogy and implicitly assuming that the soil is monolithic can provide misleading information about what kinds of rocks actually occur at a site and their relationship to each other. This concern applies equally to spectral reflectance data in which "anorthositic norite" and "noritic anorthosite" are identified [e.g., Blewitt et al., 1994].

Our approach, instead, treats a soil composition as a mathematical mixture of compositions of likely lithologic components using a least squares "mixing model." This technique works well with high-precision data obtained in the laboratory [e.g., Rhodes et al., 1974; Laul et al., 1981; Korotev and Kremser, 1992]. Mixing models are not based on a standard "recipe," as in the calculation of normative mineral proportions. Rather, any combination of components may be assumed, and some set of components not tested may provide a better mathematical fit than any set that is tested. Thus, the calculations can show that a particular set of components does or does not achieve mass balance, but a good fit does not constitute proof that the set of assumed components represents the actual rock types that make up the soil. Applied judiciously, however, mass balance can help identify actual components. Thus a secondary purpose of this paper is to test the likely success of using compositional mass balance or mixing models in identifying the major lithologic components of the regolith and determining their proportions. This approach has been used in the past without any demonstration that it actually works [e.g., Spudis and Hawke, 1981; Spudis et al., 1984; Spudis, 1993].

\subsection{Model Calculations and Weighting Factors}

The rudiments of the least squares mixing approach as applied to lunar soils are discussed by Boynton et al. [1975]. In essence, a mass-balance equation can be written for each element $i$ :

$$
Y_{i}=\sum_{j=1}^{m} y_{i, j} f_{j}
$$

where $Y_{j}$ is the calculated concentration of element $i$ in the soil, $y_{i, j}$ is the concentration of element $i$ in component $j$, and $f_{j}$ is the mass fraction of component $j$. When the number of elements, $n$, exceeds the number of components, $m$, the best fit solution, i.e., the values $f_{j}$, can be obtained by minimizing the expression

$$
\chi^{2}=\sum_{i=1}^{n} w_{i}\left(C_{i}-Y_{i}\right)^{2}
$$

where $C_{i}$ is the observed concentration of element $i$ in the soil and $w_{i}$ is a weighting factor for each element. The weighting factors are necessary to account for the large range from element to element in absolute concentrations (and a different concentration unit for $T h$ ) and the fact that some elements (e.g., Ca) are determined more precisely than others (e.g., K). In general, if $w_{i}=1 / \sigma_{i}{ }^{2}$, where $\sigma_{i}$ is the standard deviation in the population of $C_{i}$, then the quantity $\chi^{2} / v$ (reduced chisquare, where $v=n-m$ ) should approximate unity for a good fit. Values of $\chi^{2} / v$ greater than unity represent poorer fits, but values less than unity do not indicate significantly better fits. However, when major elements are modeled as in the present case, values of $\chi^{2} / v$ can be expected to be consistently less than unity for good fits because of closure $\left(\Sigma C_{t}=1\right)$ and because the various elements do not behave independently (e.g., $\mathrm{Fe}$ correlates with $\mathrm{Mg}$ ). In our model, the weighting factors are based on the expected instrument uncertainty of the $\alpha-p-x$ spectrometer. We assume that analytical uncertainty ("counting statistics") dominates $\sigma_{i}$ and that at high concentrations, $\sigma_{i} / C_{i}$ is constant $\left(r_{i}\right.$ of Table 1$)$, but at low concentrations (near the detection limit), $\sigma_{i}$ is constant $\left(\sigma_{b, i}\right.$ of Table 1$)$. Because $\mathrm{K}$ and, to a lesser extent, $\mathrm{Na}$ are determined very imprecisely, these elements provide little constraint to the model.

The solution to each fitting exercise is the set of values $f_{f}$, i.e., the relative abundances of each component in the best fit mixture. (Henceforth, we use "the "abundance" of component $j$ ' to refer to the relative proportion of the component as given by $f_{j}$.) We also calculate $\sigma_{f, j}$, the uncertainties in $f_{j}$. Note that in the least squares technique, $\Sigma f_{j}$ is not constrained to equal unity, and best fit solutions may include negative values of $f_{j}$. Negative values of $f_{j}$ occur most frequently with sets of components that include two or more components of similar composition (e.g., two different mare basalts) or when one of the components (e.g., troctolite) is reasonably well modeled as a mixture others (e.g., anorthosite and dunite).

\subsection{Simulated Low-Precision Analyses}

We have simulated compositional data obtained by an $\alpha-p-x$ spectrometer by taking high-precision data for soils and mixtures of rocks obtained in the laboratory and degrading them according to the expected uncertainties of the $\alpha-\mathrm{p}-\mathrm{x}$ spectrometer. Because the composition of Apollo 17 soils varies from station to station and, for some elements, the range of variation is great (e.g., Ti concentrations vary by more than a factor of 10 ), the response of the instrument will also vary. We have simulated the anticipated response of the instrument in the following manner. First, we have estimated instrument uncertainties for the major elements for lunar compositions. We assume from context that the uncertainties 
Table 1. Composition of Components, Analytical Sensitivities, and Weighting Factors

\begin{tabular}{lcccccccccccc}
\hline Component & $\begin{array}{c}\mathrm{O}, \\
\%\end{array}$ & $\begin{array}{c}\mathrm{Si}, \\
\%\end{array}$ & $\begin{array}{c}\mathrm{Ti}, \\
\%\end{array}$ & $\begin{array}{c}\mathrm{Al}, \\
\%\end{array}$ & $\begin{array}{c}\mathrm{Fe}, \\
\%\end{array}$ & $\begin{array}{c}\mathrm{Mg}, \\
\%\end{array}$ & $\begin{array}{c}\mathrm{Ca}, \\
\%\end{array}$ & $\begin{array}{c}\mathrm{Na}, \\
\%\end{array}$ & $\begin{array}{c}\mathrm{K}, \\
\%\end{array}$ & $\begin{array}{c}\mathrm{Th}, \\
\mu \mathrm{g} / \mathrm{g}\end{array}$ & $\begin{array}{c}\Sigma, \\
\%\end{array}$ & $\begin{array}{c}\mathbf{M g}^{\prime}, \\
\%\end{array}$ \\
\hline AN-GrF & 45.0 & 21.5 & 0.27 & 13.7 & 4.55 & 3.75 & 10.9 & 0.26 & 0.06 & 0.44 & 99.99 & 66 \\
AN-GrM & 45.0 & 20.8 & 0.17 & 14.3 & 3.73 & 4.43 & 11.0 & 0.35 & 0.07 & 0.55 & 99.85 & 73 \\
MG-TrA & 45.0 & 20.0 & 0.02 & 13.4 & 3.20 & 8.22 & 9.56 & 0.24 & 0.05 & 0.23 & 99.69 & 86 \\
MG-Tr & 44.7 & 20.1 & 0.02 & 10.7 & 4.04 & 12.1 & 7.72 & 0.15 & 0.03 & 0.13 & 99.56 & 87 \\
MG-Nor & 44.8 & 23.5 & 0.16 & 9.05 & 6.25 & 7.53 & 7.41 & 0.30 & 0.22 & 1.43 & 99.22 & 74 \\
MG-GaN & 43.9 & 22.9 & 0.49 & 8.02 & 5.91 & 6.97 & 10.2 & 0.44 & 0.10 & 1.49 & 98.93 & 73 \\
MG-Dun & 43.0 & 19.0 & 0.02 & 0.70 & 9.02 & 27.1 & 0.79 & 0.015 & 0.002 & 0.02 & 99.63 & 87 \\
IE-NB & 44.3 & 21.8 & 0.94 & 9.63 & 7.07 & 7.34 & 8.04 & 0.47 & 0.20 & 5.1 & 99.79 & 70 \\
IE-KR & 43.1 & 22.8 & 0.77 & 7.19 & 11.7 & 5.79 & 7.33 & 0.30 & 0.21 & 5.5 & 99.19 & 53 \\
MB-VLT & 42.5 & 22.7 & 0.42 & 5.72 & 13.4 & 7.06 & 6.93 & 0.13 & 0.012 & 0.08 & 98.87 & 55 \\
MB-HT & 40.5 & 18.1 & 7.37 & 4.73 & 14.6 & 5.08 & 7.76 & 0.29 & 0.04 & 0.4 & 98.47 & 44 \\
MB-OG & 40.1 & 18.0 & 5.47 & 3.06 & 17.8 & $\mathbf{8 . 9 8}$ & 5.29 & 0.28 & 0.07 & 0.4 & 99.05 & 54 \\
sensitivity* & 23. & 4.2 & 4.0 & 3.7 & 27. & 4.0 & 47. & 4.0 & 0.7 & - & & \\
$r_{i}^{\prime},(\%)$ & 3 & 11 & 28 & 18 & 6 & 20 & 5 & 90 & 400 & 25 & & \\
$\sigma_{b, t}$ & 0.2 & 0.4 & 0.25 & 0.3 & 0.1 & 0.3 & 0.1 & 0.12 & 0.12 & 0.3 & & \\
\hline
\end{tabular}

* Counts per hour per unit concentration (mass percent) of element, estimated from data of Economou and Turkevich [1992] for the $\alpha-p-x$ instrument assuming a Martian basaltic composition, a 10-hour analysis, and simple counting statistics.

${ }^{\dagger}$ Estimated analytical uncertainty (relative standard deviation, \%) for the average composition of Apollo 17 soil as determined by the $\alpha-p-x$ instrument, based on sensitivity data of the previous row and a 1 -hour analysis. For each element $i$, the value $w_{i}$ in equation (2) was calculated as $1 / \sigma_{i}^{2}$, where $\sigma_{i}^{2}=\left(r_{i} C_{i} / 100\right)^{2}+\sigma_{b, i}^{2}$ and $C_{i}$ is the "observed" (simulated) concentration of the element in the soil being modeled. The value $\sigma_{b, i}$ is an estimated "background" term to prevent $\sigma_{i}$ from becoming too small for statistically low values of $C_{l}$, thus overweighting elements with concentrations near zero (a concern primarily for $\mathrm{Na}$ and $\mathrm{K}$, and to some extent $\mathrm{Ti}$ and $\mathrm{Th}$ ).

$\mathrm{Mg}$, mole \% Mg/[Mg $+\mathrm{Fe}]$ (for information only; not used explicitly as a parameter in the modeling).

reported by Economou and Turkevich [1992] are those for a Martian basaltic composition, that they represent simple counting statistics, and that they represent a best case scenario involving a long analysis time (assumed to be 10 hours; the analysis time corresponding to their stated uncertainties is not given by Economou and Turkevich [1992]). This allows us to estimate instrument sensitivities for each element, i.e., counts per hour per unit of element concentration (Table 1). These sensitivities, in turn, allow us to calculate the number of counts expected for each element for a given soil composition and, consequently, an estimate of the analytical uncertainty from simple counting statistics. For the same analysis time, our lunar uncertainties are about the same as those stated by Economou and Turkevich [1992], but for example, relative uncertainties for $\mathrm{Al}$ in the lunar highlands are smaller because of the higher Al concentrations compared to the Martian basaltic compositions. A strategy of our simulated rover mission is that we will make measurements of short duration at many different locations. Thus we have calculated instrument uncertainties with an analysis duration one-tenth the unstated time of Economou and Turkevich [1992] (e.g., 1 hour instead of 10 hours). This increases the uncertainties of Economou and Turkevich [1992] by a factor of $10^{1 / 2}$. Our estimated instrument uncertainties are stated as relative standard deviations based on an average composition for Apollo 17 soils (Table 1).

We then used the instrument uncertainties to generate simulated analyses based on actual compositions. We will refer to a "sample" as the soil at a given location for which we want an analysis. The "true" or "actual" composition of a sample will be either those of Table 2 of Korotev and Kremser [1992] (averages by sampling station of actual Apollo 17 soils) or idealized mixtures (below). For the soil data of Korotev and Kremser [1992], we have converted oxide concentrations to element concentrations, including oxygen. Then, using a routine that generates pseudo-random values with a normal distribution of a given standard deviation about a given mean (based on an empirical solution of the inverse normal integral [Abramowitz and Stegun, 1972]), we have generated simulated analyses for each sample having the property that mean concentrations of many such simulations would correspond to the true concentrations, and standard deviations would correspond to the estimated instrument uncertainties.

This degradation procedure sometimes generates negative concentrations for $\mathrm{Ti}, \mathrm{Na}$, and $\mathrm{K}$ because of their high relative uncertainties. This result is reasonable, as concentrations will be determined by subtracting a background signal from a peak signal, and will sometimes yield a negative net signal when the peak signal is negligibly small. However, because negative or near-zero positive concentrations are unrealistic, for modeling, all concentrations for $\mathrm{Ti}, \mathrm{Na}, \mathrm{K}$, and $\mathrm{Th}$ were set to the greater of $C$, or $C_{m}$, where $C_{s}$ is the concentration value generated by the simulation procedure described above and $C_{m}$ is one-half the minimum observed concentration of the element among all Apollo 17 soils $\left(C_{m, \mathrm{~m}}=0.28 \%\right.$, $C_{m, \mathrm{Na}}=0.13 \%, C_{m, \mathrm{~K}}=0.03 \%, C_{m, \mathrm{Th}}=0.30 \mu \mathrm{g} / \mathrm{g}$ ).

\subsection{Components}

From our experience with soil samples, we observe that three or four components representing local lithologies are usually sufficient to account for $95+\%$ of the mass of most lunar soils. For ease of illustration here, we model the soils as mixtures of three components, but consider the effect of using four components.

We have selected a set of 12 components representing the range of compositionally distinct lithologies observed at the Apollo 17 site (Table 1). A few of these are rare, and there is 
no evidence that they are volumetrically important components of the regolith. For each soil sample, we try all possible combinations of the 12 components taken three at a time $(220$ combinations) and then consider only those model solutions that provide the best fits to the simulated composition. The 12 components fall into four general compositional classes: (1) anorthositic-norite highlands, (2) mafic, high- $\mathrm{Mg} / \mathrm{Fe}$ highlands, (3) mafic, high-IE highlands, and (4) mare basalt. We have obtained concentrations for 10 elements in each of these components by averaging data for numerous representative samples of the respective lithologies (Table 1); sources of data are cited in the discussion below.

3.4.1. Class AN: Anorthositic norite components. We have chosen two compositions to represent the highlands component referred to as "anorthositic gabbro" [Rhodes et al., 1974; Laul et al., 1981] or "anorthositic norite" [Korotev and Kremser, 1992]: AN-GrF and AN-GrM. Both are based on granulitic breccias and they differ from each other primarily in $\mathrm{Mg} / \mathrm{Fe}$ ratio, or $\mathrm{Mg}^{\prime}$ (mole percent $\mathrm{Mg} /[\mathrm{Mg}+\mathrm{Fe}$ ] [Lindstrom and Lindstrom, 1986]). Anorthositic norite components are important constituents of the Apollo 17 highlands and the major carrier of aluminum [Korotev and Kremser, 1992; Jolliff et al., 1994]. All previously published models have used a single component of intermediate $\mathrm{Mg}^{\prime}$ (see discussion by Korotev and Kremser [1992]).

3.4.2. Class MG: Mafic, high-Mg/Fe components. In the lunar highlands, the elements $\mathrm{Fe}$ and $\mathrm{Mg}$ are carried by two types of materials: (1) plutonic troctolites, norites, gabbronorites, their more anorthositic variants, and their brecciated derivatives and (2) impact-melt breccias of noritic or olivinenoritic composition. As noted above, the mafic impact-melt breccias are also the principal carriers of IEs in Apollo 17 soils. We use five components to represent mafic, plutonic rocks: MG-Dun, dunite (samples 72415, 72417), MG-Tr, troctolite (76535), MG-TrA, troctolitic anorthosite (72705, 73235, others), MG-Nor, norite (77035, 77075, 78255, others), and MG-GaN, gabbronorite (76255). (See Ryder and Norman [1979] for sources of data on these rocks [also Warren and Wasson, 1979b; Warren et al., 1986].) The five MG components are all characterized by relatively high values of $\mathrm{Mg}^{\prime}$ (Table 1). Rocks corresponding to the MG components are not common at Apollo 17 and only in soils from the North Massif is there any evidence that they are important constituents of the regolith (10-20\%; [Korotev and Kremser, 1992; Jolliff et al., 1994]). There is no evidence that lithologies representing the MG-Dun or MG-GaN components occur in concentrations as great as $1 \%$ in the regolith. We include these components mainly to test the robustness of the model.

3.4.3. Class IE: Incompatible-element-rich components. We use a single component, IE-NB, to represent the noritic melt breccias that are common at the site [Rhodes et al., 1974; Korotev and Kremser, 1992]. We also include a component of Apollo 17 KREEP basalt, IE-KR [Salpas et al., 1987], which is similar in composition to the noritic melt breccia, but has a distinctly different $\mathrm{Mg}^{\prime}$ and $\mathrm{Ca} / \mathrm{Al}$ ratio (Table 1). Because these two components are the principal carriers of IEs in the Apollo 17 regolith, their model-predicted abundance is determined largely by the concentration of $T h$. There is little evidence that IE-KR is anything but a minor component in the Apollo 17 highlands; its occurrence is restricted to portions of a single breccia [Blanchard et al., 1975; Salpas et al., 1987]. Two IE components are included in the model, however, to test the ability of the rover instru- ments to distinguish between these compositionally similar, but texturally distinct, components and to identify a deposit of KREEP basalt, if one were to occur.

3.4.4. Class MB: Mare basalts. Three mare like components occur at the Apollo 17 site: MB-HT, high-Ti basalt (data from Korotev and Kremser [1992]); MB-OG, orange picritic glass of pyroclastic origin [Delano, 1986]; and MB-VLT, very low Ti basalt [Korotev and Kremser, 1992]. (Discussion of these various basalt types can be found in the review of Taylor et al. [1991].) The MB and MG components are the principal carriers of $\mathrm{Fe}$ and $\mathrm{Mg}$, but the $\mathrm{MB}$ components have substantially lower values of $\mathrm{Mg}^{\prime}$ (Table 1). Also, MB-HT and MB$\mathrm{OG}$ are the principal carriers of $\mathrm{Ti}$ in the Apollo 17 regolith. VLT basalt is rare and only known from a few small fragments [Wentworth et al., 1979; Lindstrom and Martinez, 1995]. We include it in the model for the same reason we include KREEP basalt.

\section{Reasonableness of Approach: Tests Using High-Precision Analyses of Real Soils}

I.efore proceeding with application of the mixing-model approach to simulated soil compositions, we demonstrate that the model provides reasonable results on high-precision soil compositions.

\subsection{Preliminary Test 1}

Our approach assumes that a 10-element model based primarily on major elements is mathematically well constrained. A test of this assumption is whether results of the 27-element model of Korotev and Kremser [1992] (hereafter, the $\mathrm{K} \& \mathrm{~K}$ model) can be reproduced with the 10-element model when exactly the same components and component compositions are used. (Some of the components of the K\&K model are mixtures of components described here and others have slightly different compositions.) The two models differ, then, in (1) number of elements, (2) magnitude of weighting factors, (3) the implicit inclusion in the 27-element model of a 28 th element, oxygen, whereas in the 10 -element model it is included explicitly, and (4) the meteoritic component of the 27-element model is excluded from the 10-element model because it relies on constraints imposed by siderophile element concentrations (not determined by the $\alpha-p-x$ spectrometer) and is of minor volumetric importance $\left(f_{j}<0.01\right)$.

We have modeled the mean compositions [Korotev and Kremser, 1992] of soils from five stations that span the range of observed compositions. The predicted values of $f_{j}$ (relative abundances of components; equation (1)) are usually within $\pm 5 \%$ for the two models, which we regard as reasonable agreement. (Here and subsequently, in discussion of model results $\left(f_{j}\right)$ or differences in model results $\left(f_{j}-f_{k}\right)$, the percent sign (\%) signifies "grams of component per 100 grams of soil," not a relative difference between two values.) The principal exception is that, although the sums of the proportions of the three basaltic components agree well between the two models, the relative proportions of high-Ti basalt (MB-HT) and orange glass (MB-OG) often do not. Trace elements $(\mathrm{Cr}$, rare earth elements) help constrain the proportions better in the 27-element model.

\subsection{Preliminary Test 2}

A second question is whether using the 10-element model and selecting the best solutions among all combinations of 12 
components taken three at a time provides realistic results for high-precision soil compositions. For this test, we have modeled the mean compositions of soils from stations $2,4,5$, and 6 [Korotev and Kremser, 1992]. Although the test is based on laboratory data, the results are also relevant to longduration (i.e., high-precision) analyses of soils or breccias by the $\alpha-p-x$ spectrometer on the lunar surface.

We apply three filters to yield a set of "best solutions" from the 220 possible solutions for each soil. First, we discard most solutions that include a negative value of $f_{j}$, as most negative values result from an unreasonable set of components (e.g., fitting a mare soil with three highland components). We do not discard a negative solution if $f_{j}>-5 \%$ and $f_{j}+\sigma_{f, J}>0 \%$; i.e., if $f_{j}$ is negative, small, and zero within uncertainty, we take the solution to indicate that $f_{j}=0$. Second, we discard any solution for which $f_{j}-\sigma_{f, j}<0$ for all values of $f_{j}$ (e.g., $f_{1}=60 \% \pm 62 \%, f_{2}=7 \% \pm 78 \%$, and $f_{3}=$ $30 \% \pm 41 \%$ ), a condition indicating that the least squares solution is of little value. Third, we discard all solutions for which $\chi^{2} / v>0.5$; we choose the value 0.5 empirically to eliminate all but the best numerical solutions. (Because in this test we are modeling high-precision analyses, but using weighting factors based on the lower precision of the $\alpha-\mathrm{p}-\mathrm{x}$ spectrometer, we can expect values of $\chi^{2} / v$ for the best solutions to be significantly less than unity.) The remaining solutions are then the "best solutions" for each composition, and they usually number between 10 and 30 . We assume that all best solutions are equally good, regardless of differences in $\chi^{2} / v$.

4.2.1. Station 5 (valley floor). For soils that consist principally of one or two components, the modeling of the highprecision analyses recognizes the presence of the main components, but not always the minor components. For example, we obtain 49 best solutions for the station 5 soil, which consists mainly of pulverized high-Ti mare basalt. Each best solution is reasonable and successful in that it includes the MB-HT component. Most solutions $(N=32)$ use only MB-HT as the $\mathrm{MB}$ component; others use MB-HT plus MB-OG $(N=7)$ or MB-VLT $(N=9)$. The sum of the MB components averages $89 \pm 3 \%( \pm 1 \sigma)$, agreeing well with the K\&K model, which gave $76 \% \mathrm{HT}, 7 \% \mathrm{VLT}$, and $6 \%$ OG components, for a sum of $89 \%$. For those 10 -element solutions that include $O G$ or VLT, the abundances average $11 \pm 9 \%, O G$ and $13 \pm 6 \%$ VLT, in reasonable agreement with the K\&K model. Best solutions include a wide variety of components to account for the other $11 \%$ of the soil, with MG components in 37 of the solutions, IE components in 18, and AN components in 16 . The high proportion with MG components occurs because the station 5 soil has a significantly greater concentration of $\mathrm{Mg}$ than can be explained even by the 27 -element, six-component model [Korotev and Kremser, 1992]. Thus the mixing-modeI approach successfully recognizes that the station 5 soil is approximately a 90:10 mixture of high-Ti mare basalt and highlands materials. Similar results are obtained for the soil at station 1, which is also rich in high-Ti mare basalt.

4.2.2. Station 2 (South Massif). In the K\&K model, the station 2 soil at the South Massif was modeled well as $46 \%$ IE components (mostly IE-NB plus minor IE-KR), 47\% AN components, and about 2-3\% each MB-HT and MB-OG components. Of the 17 best solutions from the 10 -element model, seven are qualitatively equivalent to that of the $K \& \mathrm{~K}$ model (i.e., $\mathrm{E}+\mathrm{AN}+\mathrm{MB}$ ). Nine solutions include an $\mathrm{MB}$ component, which averages $5 \pm 3 \%$ in abundance, thus agreeing well with the total MB component of the K\&K model; no preference is shown for any particular MB component. All 17 best solutions include an IE component; 16 use IE-NB, one uses IE-KR, and two use both (but predominately IE-NB), in accordance with the observation that the main carrier of IEs at station 2 to is noritic melt breccia, not KREEP basalt. The sum of IE components averages $58 \pm 9 \%$, however, significantly greater than the $46-48 \%$ of the K\&K model. This disagreement is not a model failure, but occurs because the concentration of Th is greater in the AN component of the $K \& \mathrm{~K}$ model. Twelve of the 17 solutions include an AN component, which averages $33 \pm 12 \%$. There is no preference between the AN-GrF or the AN-GrM components, suggesting (as assumed by Korotev and Kremser [1992]) that the actual AN component of the regolith is a mixture of anorthositic norite lithologies intermediate in $\mathrm{Mg}$ ' to the two extreme AN components used here.

Results of the 10-element model are misleading, however, to the extent that seven of the 17 best solutions include a substantial proportion of MG components (average $36 \pm 13 \%$ ), in five cases instead of an $\mathrm{AN}$ component. In each of these cases, the MG-GaN component was selected. Gabbronorite (not included in the K\&K model) is rare at Apollo 17, and we find no evidence of its presence in station 2 soil [Jolliff et al., 1994]. This model failure is probably related to several factors: (1) nonuniqueness of the gabbronorite composition, (2) the lack in the 10-element model of the constraints imposed by trace elements, and (3) the presence of an unidentified, cryptic component at station 2, possibly the new type of high-Th, low-Mg/Fe, noritic melt breccia recently recognized among 2-4 mm soil particles [Jolliff et al., 1995]. If a component representing this new lithology is used in the $K \& K$ model instead of the KREEP basalt component used by Korotev and Kremser [1992], the model fit is improved, and the results indicate the component is present at $13 \%$ relative abundance.

4.2.3. Station 6 (North Massif). Soils from the North Massif provide challenge to mixing models because they consist of several volumetrically significant, compositionally distinct lithologies. The challenge is most severe at station 6 in which all four classes of components are important at the 15-35\% abundance level [Korotev and Kremser, 1992].

The 10-element, three-component model gives only 13 best solutions. The model is successful in that eight of these contain some combination of $I E, A N$, and $M B$, the three most important components of the K\&K model. All 13 solutions contain one MB component (nine HT and four OG), and the fraction of this component averages $26 \pm 3 \%$, in good agreement with the K\&K model (27\%). Ten of the best solutions include an IE component (five NB and five $\mathrm{KR}$ ), average $27 \pm 5 \%$, in reasonable agreement with $K \& K(21 \%)$. Five of the solutions contain one or two MG components, average $43 \pm 21 \%$, which compares poorly with $15 \%$ in the K\&K model. The discrepancy occurs because with only three components, all solutions involving an MG component necessarily exclude either the AN or the IE component, and the MG component has to act as either an MG+AN or an MG+IE component.

The results for station 6 suggest that better results may be obtained with a four-component model, so we repeated the modeling exercise using 12 components taken four at a time. Of 495 possible combinations, we obtained 74 best solutions, significantly more than the 13 of the three-component model. 
Of these, 33 represent combinations involving all four classes of components, with average abundances in close agreement with the $\mathrm{K} \& \mathrm{~K}$ model (in parentheses): $\mathrm{AN}, 35 \%$ (36\%); $\mathrm{MG}$, $17 \%$ (15\%); IE, 23\% (21\%); and MB, 25\% (27\%). This example shows that in some cases a four-component model will produce superior results to a three-component model. However, if a soil consists dominantly of only two or three components, results of four-component models are not necessarily better and are more difficult to interpret. For example, the four-component model applied to the station 2 soil does not provide any additional insight and still erroneously suggests the presence of $\sim 20 \% \mathrm{MG}-\mathrm{GaN}$ component.

As stated above, the $\chi^{2} / v$ parameter is not useful for identifying the most reasonable solution among the set of solutions with the lowest values of $\chi^{2} / v$. For example, in the four-component model for station 6 , the mathematically best solution has an exceedingly low $\chi^{2} / \nu(0.01)$, yet erroneously predicts a $15 \%$ component of KREEP basalt.

4.2.4. Station 4 (orange-glass soil). The three-component model gives 38 best solutions for the orange-glass soil from station 4. (Unlike the K\&K model, the MB-OG component used here represents the glass; the soil composition is based on fines sample 74220.) All 38 solutions successfully indicate the presence of the MB-OG component at high abundance $(86-96 \%)$. For the 17 solutions that include two or three MB components, the actual proportion of orange glass, as determined by petrographic studies [Heiken and MCKay, 1974], is estimated best by the sum of all MB components, $96.0 \pm 1.3 \%$. The remaining $\sim 4 \%$ was modeled as various combinations of nonmare components, each used at least once, with no preference for any component or any class of components, except that MG components are included in half of the solutions. Among solutions including MG components, the MG-GaN was selected most often (7) and MG-Dun least often (1). These model results involving the abundance and distribution of $\mathrm{MG}$ components are unreasonable, as there is no petrographic evidence for high- $M g^{\prime}$ lithologies in the station 4 regolith.

4.2.5. Summary. Ideally, the actual components of the regolith would be known, the average compositions of those components would be known well, the major element compositions of the soils could be measured accurately, and the concentration of at least one incompatible element could be determined. Under these circumstances, our approach of "fishing" among all combinations of the likely components for the three-component mixtures that best duplicate the soil composition does, in fact, usually succeed in identifying the major classes of components of the soil (i.e., MB, IE, AN, or MG) and reasonably indicating their relative abundances. The specific member of the class is not likely to be identified unambiguously unless it is present in high abundance (>50\%). For soils that contain significant fractions of more than three components (e.g., station 6), the distribution of the three best fit components among different classes will be variable, and a four-component model will provide more realistic results. Minor components of the soil $(<25 \%)$ are likely to be misidentified and their proportions estimated poorly.

\section{Simulation 1A: Traverse of an Idealized Site}

A logical next step would be to degrade the actual compositions of soils from the Apollo 17 mission according to the expected analytical precision of the $\alpha-\mathrm{p}-\mathrm{x}$ instrument and then repeat the test described above. A problem with this ap- proach, however, is that there is no objective way to evaluate the results. Above, we compared the results with those of Korotev and Kremser [1992], which is valid for the declared purpose, i.e., comparing the results for a given soil composition of a 10-element model involving primarily major elements with a better constrained, 27-element model that includes trace elements. However, the $\mathrm{K} \& \mathrm{~K}$ model is itself an imperfect one that involves numerous assumptions and compromises. Thus, to provide a test that can be judged more objectively, we have computed a series of simulated soil compositions by mathematically mixing our lithologic components in known proportions and then generating simulated analyses by degrading the compositions of the simulated mixtures, as described above. For reference, Table 2 contains the actual and simulated compositions of two samples.

\subsection{Site Geology and Traverse Grid}

In order to simulate an actual mission more realistically, we have based our mixtures on an idealized site geology where certain lithologies predominate at different locations at the site and the soils represent mixtures of the subsurface lithologies. At this idealized site (Figures 1 and 2), which is based only loosely on the actual Apollo 17 site geology, the top of the North Massif (grid stations AO to JO) consists primarily of IE-NB components (70\%), with some MG components (30\%). The MG components systematically vary from west to east in the order MG-TrA, MG-Tr, MG-Nor, MGGaN. On the lower slopes of the North Massif, AN components predominate, with $A N-G r F$ more prevalent to the west and AN-GrM more prevalent to the east. Soils of the lower slopes are mixtures of $\mathrm{AN}$ components and IE-NB and MG components that have wasted down the slope. The South Massif is similar, except that no MG components occur and the AN-GrF component dominates over the AN-GrM component. To add some diversity, however, the western extreme of the top of the South Massif (near grid station A9) is dominated by IE-KR, not IE-NB. The valley floor is mainly MBHT with some minor highland material, except that in the southeast comer of the traverse area there is a concentration of MB-OG, such as occurred at station 4 at the Apollo 17 site. Also, on the east central edge of the area, there is a concentration of MB-VLT (no such concentration is known at the

Table 2. Actual Composition (A), Simulated Analysis (S), and Model Best Fit (M) Composition for Two Grid Stations of Simulation $1 \mathrm{~A}$

\begin{tabular}{|c|c|c|c|c|c|c|}
\hline & \multicolumn{3}{|c|}{ Station F7 } & \multicolumn{3}{|c|}{ Station F2 } \\
\hline & A & $S$ & M & A & $S$ & $\mathbf{M}$ \\
\hline $0, \%$ & 43.58 & 46.22 & 45.31 & 44.75 & 44.22 & 44.19 \\
\hline $\mathrm{Si}, \%$ & 20.42 & 18.90 & 21.38 & 21.34 & 22.96 & 20.52 \\
\hline $\mathrm{Ti}, \%$ & 2.46 & 2.84 & 2.16 & 0.40 & 0.28 & 0.37 \\
\hline $\mathrm{Al}, \%$ & 10.64 & 9.75 & 11.52 & 12.37 & 11.02 & 12.10 \\
\hline $\mathrm{Fe}, \%$ & 7.74 & 7.31 & 7.50 & 4.98 & 4.54 & 4.60 \\
\hline $\mathrm{Mg}, \%$ & 4.57 & 4.09 & 4.52 & 5.61 & 6.82 & 7.10 \\
\hline $\mathrm{Ca}, \%$ & 9.66 & 10.33 & 10.20 & 9.76 & 9.16 & 9.19 \\
\hline $\mathrm{Na}, \%$ & 0.30 & 0.18 & 0.29 & 0.38 & 0.44 & 0.34 \\
\hline $\mathrm{K}, \%$ & 0.07 & 0.06 & 0.07 & 0.13 & $-0.45^{*}$ & 0.10 \\
\hline $\mathrm{Th}, \boldsymbol{\mu g} / \mathrm{g}$ & 0.91 & 0.96 & 0.84 & 2.00 & 2.13 & 1.97 \\
\hline$\Sigma, \%$ & 99.44 & 99.68 & 102.95 & 99.71 & 99.45 & 98.51 \\
\hline$M g^{\prime}, \%$ & 57.6 & 56.2 & 58.1 & 72.1 & 77.5 & 78.0 \\
\hline
\end{tabular}

* This value was converted to +0.03 prior to modeling; see section 3.3 . 


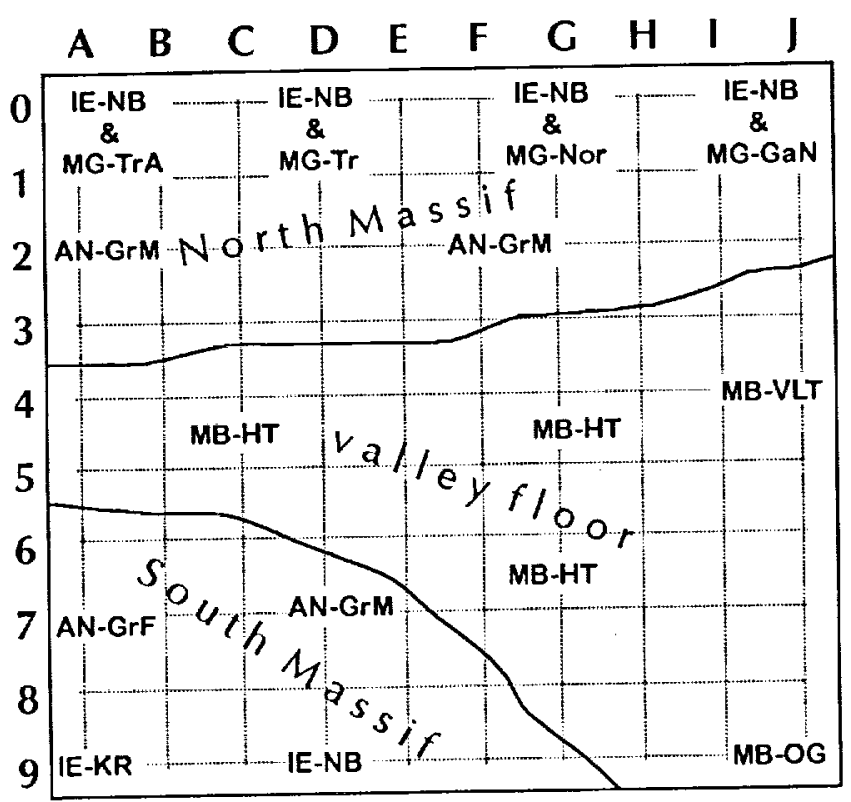

Figure 1. Site map for simulation 1 , with $10 \times 10$ sampling grid. The site is based loosely on the Apollo 17 landing site, in that a valley filled with mare basalt lies between two highland massifs. Locations of high concentrations of specific subsurface lithologies (model components) are indicated (MBHT, AN-GrM, etc.; see section 3.4 for definition of components).

Apollo 17 site). At the interface between the massifs and the valley floor, mixing of highland and mare material occurs, as in the Taurus-Littrow valley.

In the simulated mission, 100 soil samples are each analyzed once on a $10 \times 10$ grid. The mixture at each "grid station" was calculated according to the proportions of Figure 2. All "samples" are ideal mixtures of two, three, or four components, the abundances of the components occur in increments of 10\% (e.g., a 10:30:60 mixture), and no two samples have exactly the same composition. The simulated compositions are mixtures of all components of Table 1 except the MG-Dun component. The dunite component was excluded for simplicity because there are already four other MG components and the test using real soil compositions (preliminary test 2) selected this component least often. Because the rover will analyze each soil only once, we have generated only one simulated analysis per grid station. In order to determine the components of each sample, the 10-element model using 12 components taken three at a time was employed (i.e., the MG-Dun component was included as a model component but not as an actual component of any sample).

\subsection{Analysis of Model Results}

If 100 chemical analyses are made, some will be more accurate than others because of random uncertainty; in a real mission, some analyses may also suffer from systematic error. Thus one concern is whether an entire analysis should be ignored because it does not meet certain criteria for accuracy and precision. For example, a sum of element concentrations $\left(\Sigma C_{i}\right.$, equation (2)) significantly different from unity or concentrations yielding nonsensical normative mineral proportions probably indicate a "poor analysis," one likely to lead to a misleading interpretation. Also, in our simulated mission involving ideal mixtures of model components, we know that the only cause of a poor model fit is the random uncertainty associated with the analysis, so a high value for the minimum $\chi^{2} / v$ unambiguously indicates a poor analysis, one we might be entitled to discard. In a real mission, however, high values of the minimum $\chi^{2} / v$ for a given analysis might also reflect a model inadequacy, e.g., the presence of an unanticipated component in the soil, one not included in the model. Thus, in order to test the robustness of the model, we have not discarded from consideration any analysis from our simulated mission just because we questioned its accuracy or model results based on the analysis consistently yielded high values of minimum $\chi^{2} / v$ (some samples for which the minimum $\chi^{2} / v$ was high still provided reasonable model results). In a real mission, criteria for discarding analyses could be established.

As before, however, some criteria must be used to select "best solutions" among the 220 possible solutions for each analysis. When using simulated low-precision data, different criteria must be used to select best solutions than are used with high-precision data. In the test involving high-precision data, we arbitrarily discarded from consideration all solutions for which $\chi^{2} / v>0.5$ because minimum values of $\chi^{2} / v$ are similar for all samples. With low-precision data, minimum values of $\chi^{2} / v$ vary greatly from sample to sample as a result of low-probability aberrant concentrations for some elements in some samples, and a single cutoff value for $\chi^{2} / v$ is not feasible. For example, minimum values of $\chi^{2} / v$ ranged from 0.04 to 1.6 among the different samples (mean 0.5; Figure 3e).

With these considerations in mind, we have used the following criteria to select best solutions among model results for each simulated analysis. As described above, most solutions that included negative values of $f_{j}$ or exceedingly high values of $\sigma_{f, j}$ were discarded. Then, for each sample, if $X_{\min }$ is the minimum value of $\chi^{2} / v$ obtained among remaining model solutions, all solutions for which $\chi^{2} / v>1.5 X_{\min }$ were discarded. The factor 1.5 was selected empirically to yield a small, but reasonable number of best solutions for each analysis (mean $=13$ best solutions per analysis; Figure $3 \mathrm{~d}$ ). As before, this approach assumes that all of the model solutions with low values of $\chi^{2} / v$ (i.e., $\chi^{2} / v \leq 1.5 X_{\min }$ ) are equivalently good solutions and we seek systematic results among this set of best solutions.

\subsection{Results}

5.3.1. By class. We first consider the success of the $\alpha-p-x$ spectrometer combined with the mixing model at identifying classes of components and determining their proportions; later we consider how well the combination distinguishes among components within the same class. Among the best solutions for each station, we have combined and averaged the results by class according to the examples of Table 3. As examples of how the data were combined, we discuss results in detail for two grid stations, F7 and F2. A comparison of the actual, simulated, and model best fit composition of the two stations is given in Table 2.

5.3.1.1. Station F7: For the soil at grid station F7 there are 14 best solutions, with $\chi^{2} / v$ values ranging from 0.62 to 0.80 . i.e., all best solutions provide good fits. Only four solutions agree by class with the actual components of the mixture, and the average of their model-predicted abundances are reasonable (actual abundances in brackets): $69.5 \% \mathrm{AN}[60 \%]$, 

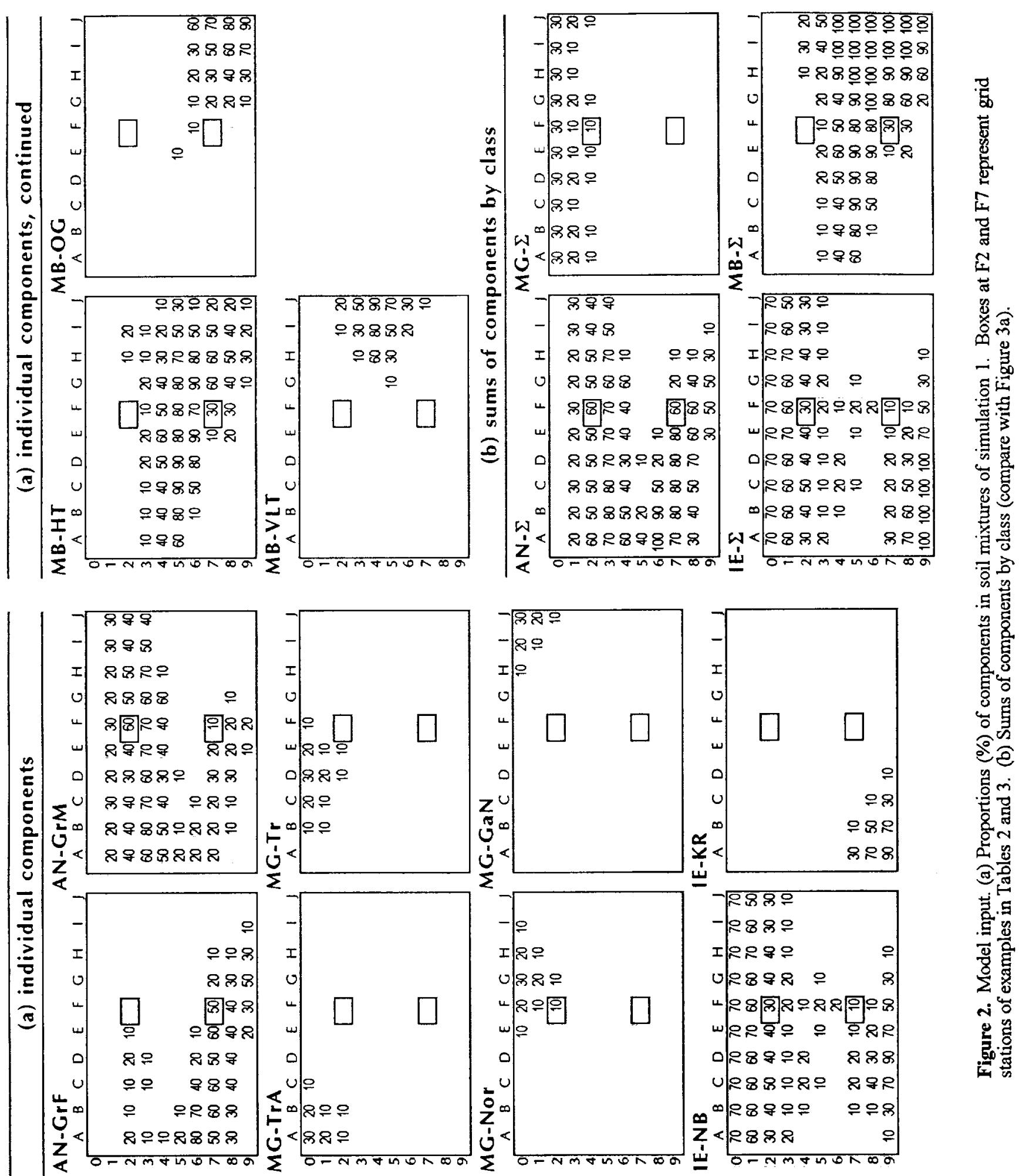

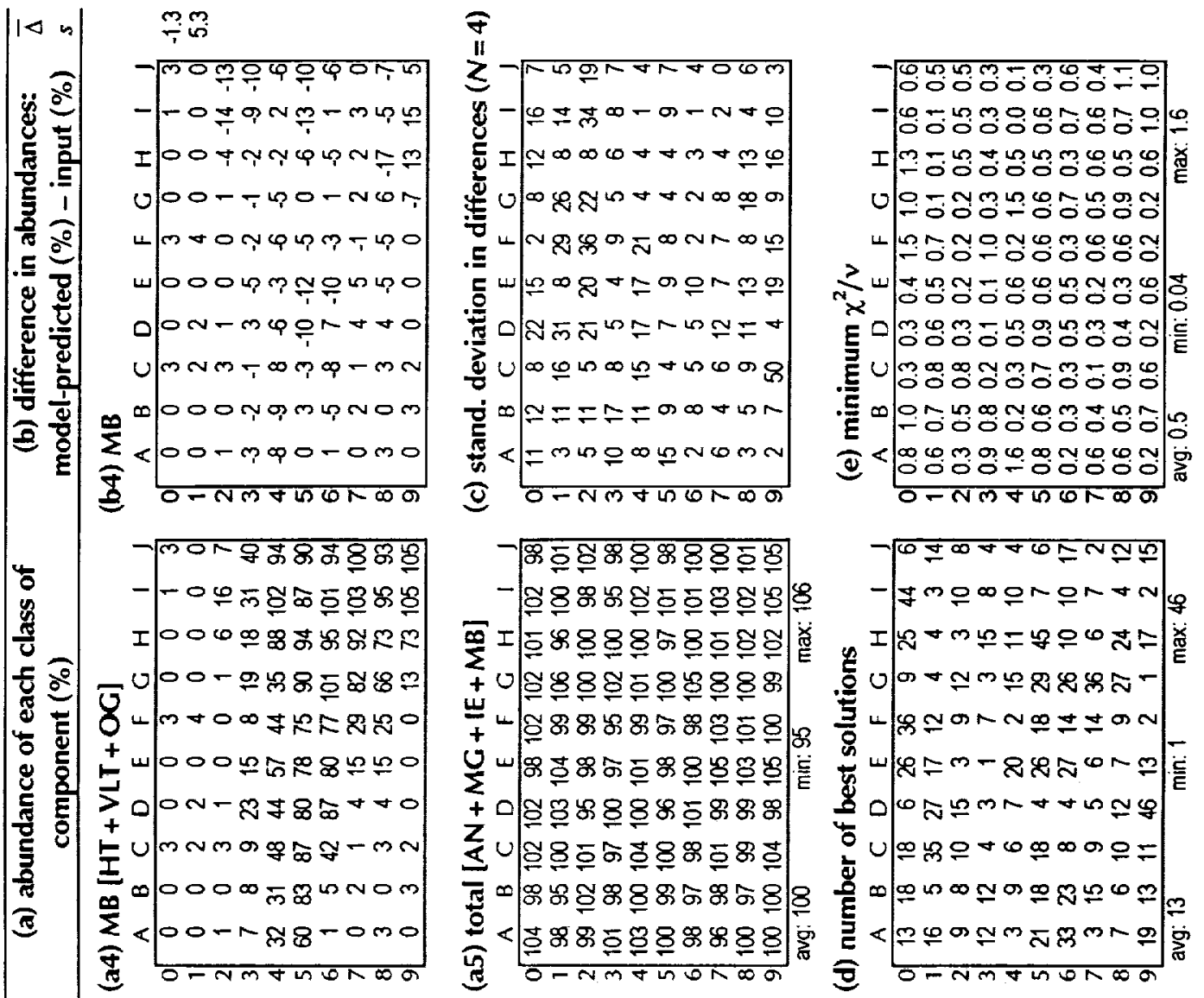

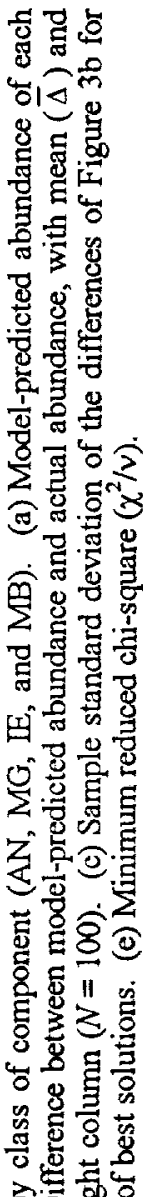

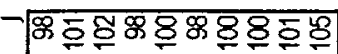

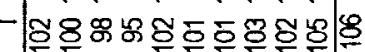

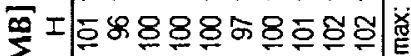

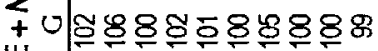

世4

Uㄴ

+0 으요요요요

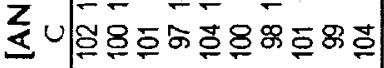

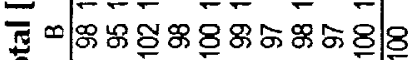

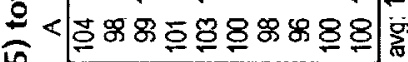

บ

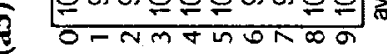

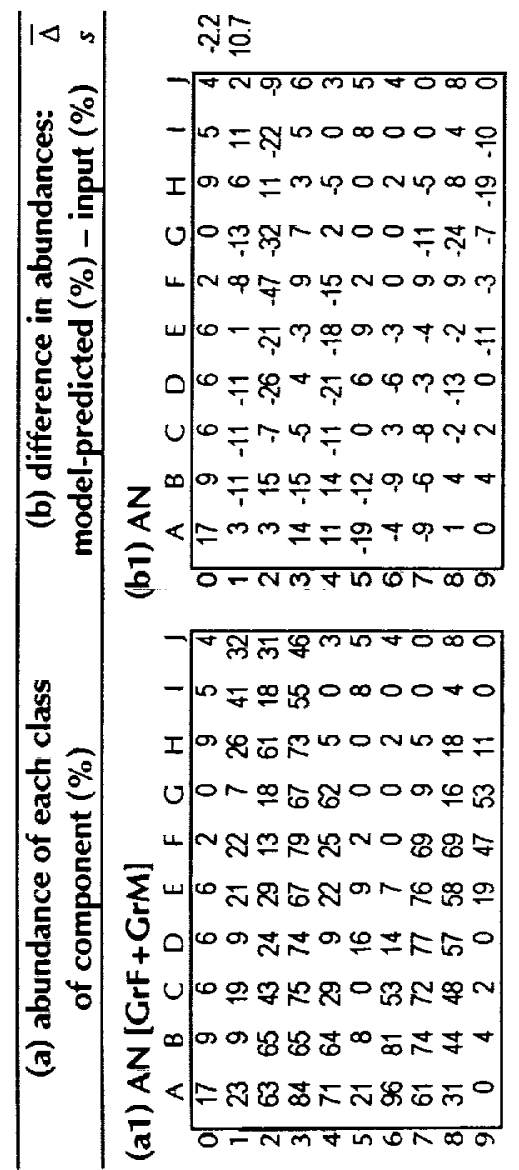

일

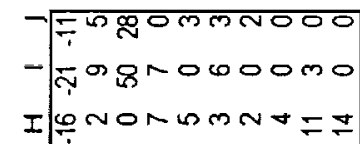

$v=8 \infty 0 \forall \omega \nabla \sigma \infty O$

NTñ

-

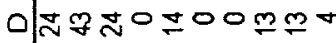

uU U U ה

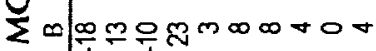

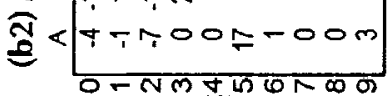

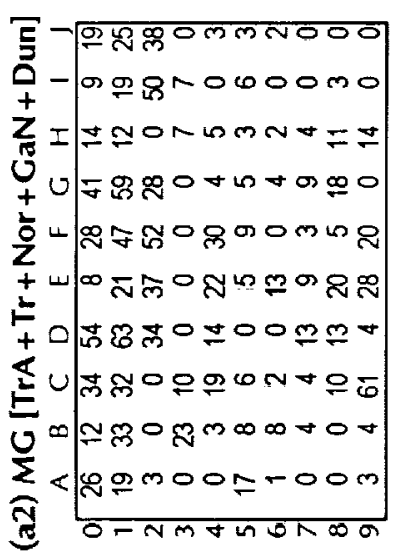

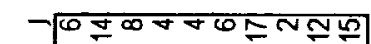

- Imboobrontaid

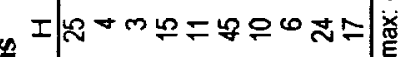

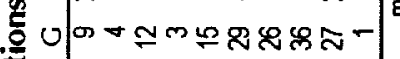

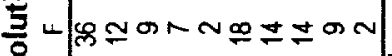

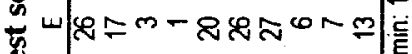

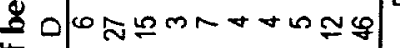

눈

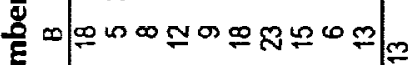

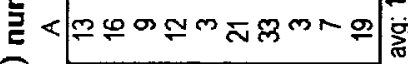

으

Ұำ

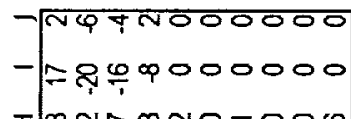

I

U की शु.

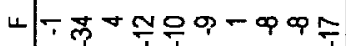

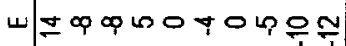

- कूष प .

UЕ

ontropomat:

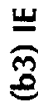

$\frac{1}{3}<$

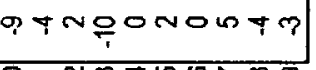

- Nanjo00000

- ntano00000

I g \& MnNo-00\%

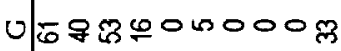

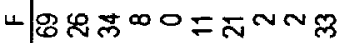

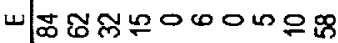

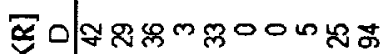

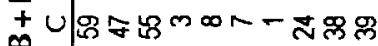

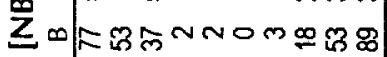

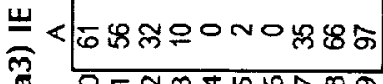

$\leq$ 尊

ธํ.

궁

资

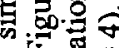

¿ स. जू

可数了

勇 돈

的 
Table 3. Summary of Model Results (Best Solutions) for the Two Grid Stations of Table 2 (Simulation 1A)

\begin{tabular}{|c|c|c|c|c|c|c|c|c|c|c|c|c|}
\hline & \multicolumn{12}{|c|}{ Percent of Component Class } \\
\hline & \multicolumn{6}{|c|}{ F7 (Typical Fit, Good Match) } & \multicolumn{6}{|c|}{ F2 (Good Fit, Poor Match) } \\
\hline & $\mathrm{AN}$ & MG & IE & $\mathrm{MB}$ & $\Sigma$ & $N^{*}$ & $\mathrm{AN}$ & MG & IE & $\mathrm{MB}$ & $\Sigma$ & $N^{*}$ \\
\hline $\mathrm{AN}$ & & & & & & 0 & & & & & & 0 \\
\hline MG & & & & & & 0 & & & & & & 0 \\
\hline $\mathrm{AN}+\mathrm{MG}$ & & & & & & 0 & & & & & & 0 \\
\hline $\mathrm{IE}$ & & & & & & 0 & & & & & & 0 \\
\hline $\mathrm{AN}+\mathrm{IE}$ & & & & & & 0 & & & & & & 0 \\
\hline$\overline{M G}+\mathrm{IE}$ & & & & & & 0 & 0 & 63.7 & 36.7 & 0 & 100.4 & 6 \\
\hline $\mathrm{AN}+\mathrm{MG}+\mathrm{IE}$ & & & & & & 0 & 26.6 & 40.2 & 31.9 & 0 & 98.7 & 3 \\
\hline $\mathrm{MB}$ & & & & & & 0 & & & & & & 0 \\
\hline $\mathrm{AN}+\mathrm{MB}$ & 73.0 & 0 & 0 & 30.3 & 103.4 & 8 & & & & & & 0 \\
\hline $\mathrm{MG}+\mathrm{MB}$ & & & & & & 0 & & & & & & 0 \\
\hline $\begin{array}{l}A N+M G+M B \\
I E+M B\end{array}$ & 65.7 & 8.9 & 0 & 28.9 & 103.5 & $\begin{array}{l}2 \\
0\end{array}$ & & & & & & $\begin{array}{l}0 \\
0\end{array}$ \\
\hline$A N+I E+M B$ & 69.5 & 0 & 6.5 & 27.5 & 103.5 & 4 & & & & & & 0 \\
\hline $\mathrm{MG}+\mathrm{IE}+\mathrm{MB}$ & & & & & & 0 & & & & & & 0 \\
\hline \multirow{3}{*}{$\begin{array}{l}\text { Mean }{ }^{\dagger} \text { or sum } \\
\text { Input }\end{array}$} & 69.4 & 3.0 & 2.2 & 28.9 & 103.5 & 14 & 13.3 & $\mathbf{5 2 . 0}$ & 34.3 & 0 & 99.6 & 9 \\
\hline & 60. & & 10 & 30. & 100.0 & & 60. & 10. & 30. & & 100 & \\
\hline & $M_{j}^{\ddagger}$ & & $\begin{array}{l}\text { Input } \\
f_{j}, \%\end{array}$ & & & & $M_{j}^{\ddagger}$ & & $\begin{array}{l}\text { Input } \\
f_{j}, \%\end{array}$ & & & \\
\hline AN-GrF & 8 & & 50 & & & & 1 & & & & & \\
\hline AN-GrM & 7 & & 10 & & & & 2 & & 60 & & & \\
\hline MB-HT & 14 & & 30 & & & & 0 & & & & & \\
\hline MB-OG & 0 & & & & & & 0 & & & & & \\
\hline MB-VLT & 0 & & & & & & 0 & & & & & \\
\hline MG-Nor & 0 & & & & & & 0 & & 10 & & & \\
\hline MG-GaN & 2 & & & & & & 1 & & & & & \\
\hline MG-Tr & 0 & & & & & & 1 & & & & & \\
\hline MG-TrA & 0 & & & & & & 8 & & & & & \\
\hline MG-Dun & 0 & & & & & & 0 & & & & & \\
\hline IE-KR & 2 & & & & & & 0 & & & & & \\
\hline IE-NB & 2 & & 10 & & & & 9 & & 30 & & & \\
\hline$N_{\mathrm{tot}^{*}}$ & 14 & & 100 & & & & 9 & & 100 & & & \\
\hline
\end{tabular}

* $N$, number of best solutions with the combination of component classes corresponding to the row label; $N_{\text {lot }}$ total number of best solutions

Simple mean; these values are those transferred to "maps" of Figure 3.

${ }^{\ddagger} M_{1}$, frequency of occurrence: number of times component was used in the various best solutions.

$6.5 \%$ IE [ $10 \%]$, and $27.5 \% \mathrm{MB}$ [30\%]. Eight best solutions use two-component mixtures of $\mathrm{AN}$ (average: $73 \%$ ) and $\mathrm{MB}$ (30\%) components and the two remaining best solutions use AN (66\%), MG (9\%), and MB (29\%) components. For purposes of reporting results on the map of Figure 3, we simply averaged results for each of the class combinations; other methods could be used. All best solutions for station F7 correctly include the MB-HT component and reasonably indicate its abundance, even though this component constitutes only $30 \%$ of the soil. Similarly, all best solutions correctly include one of the two AN components and reasonably estimate its abundance (i.e., within 10\%). The model fails to establish unambiguously the presence of the $10 \%$ component of IE-NB.

5.3.1.2. Station F2: For soil at grid station F2, the mathematical fit for the nine best solutions is better than for station F7 $\left(\chi^{2} / v=0.24-0.33\right)$, but the quantitative match to the actual mixture is poorer. All solutions correctly predict the presence of IE-NB (model average abundance $34 \%$, actual $30 \%$ ), but the match for the ratio of $A N$ to $M G$ components is poor (model average 13:52, actual 60:10). No solution suggests the presence of MG-Nor, which occurs at $10 \%$ abundance. The major error is that eight of the nine best solutions choose
MG-TrA (troctolitic anorthosite) as a major component (average abundance 58\%) instead of the AN-GrM component (magnesian granulite, actual abundance $60 \%$ ). This error occurs because (1) the compositions of the AN-GrM and MGTrA components are similar, except that the MG-TrA component has twice the $\mathrm{Mg}$ concentration (Table 1) and (2) the simulated composition of the soil at station $F 2$ has a higher concentration of $\mathrm{Mg}$ and lower concentrations of $\mathrm{Al}, \mathrm{Fe}$, and Ca than the actual composition (Table 2).

5.3.1.3. Summary of results for all stations: Of the four classes of components, the model is most successful at identifying the abundance of mare basalt in that the mean difference between the model predicted abundances and true abundances for the 100 stations, a quantity we designate $\vec{\Delta}$ (Figure 3 ), is most nearly zero and has the smallest standard deviation $(\bar{\Delta}=-1.3 \% \pm 5.3 \%$, mean difference in abundance \pm standard deviation; Figure $3 \mathrm{~b} 4$ ). For only seven of the 100 stations does the difference in abundance between the actual and predicted total $\mathrm{MB}$ component exceed $10 \%$. Only rarely does the model suggest that $\mathrm{MB}$ components are present at stations for which none are present. The average abundance of $A N$ components is also well established $(\bar{\Delta}=-2 \% \pm 11 \%$; Figure 
$3 \mathrm{bl}$ ), but the spread is greater, i.e., for 29 of the stations the difference in abundance exceeds $10 \%$, with the largest difference, 47\%, at station F2 (discussed above). As for station F2, the model is least successful at establishing the abundance of the MG components. On average, the abundance of MG components is overestimated by $8 \%$ (Figure $3 \mathrm{~b} 2$ ), with 36 of the stations having differences exceeding $10 \%$. The model commonly predicts the occurrence of MG components at stations for which none is present (worst case: $+61 \%$ at station (9) and sometimes significantly underestimates their abundance in soils where they are a significant component (stations E0 and $\mathrm{I} 0$ ). Plutonic troctolitic anorthosite cannot be reliably distinguished from polymict magnesian granulite. On average, IE components are slightly underestimated ( $\bar{\Delta}=-4.4 \% \pm 10.2 \%$; Figure $3 \mathrm{~b} 3$ ).

In summary, using major-element data obtained with the $\alpha-p-x$ spectrometer and data for an incompatible element obtained with some auxiliary instrument, the mixing-model technique described here is reasonably successful on average at distinguishing among generic components (anorthositic norite, $\mathrm{Mg}$-rich plutonic rocks, KREEP norites, and mare basalt) and estimating their proportions in the soil, even with short analysis times. Results for some individual samples, however, may be substantially in error because of the imprecision of the analyses. The model systematically overestimates the abundance of MG components, presumably because of (1) the similarity in compositions between the MG components and some other components and (2) the imprecision of the data, particularly $\mathrm{Mg}$ concentrations (Table 1), resulting from the short analysis times.

5.3.2. By component. The model is less successful at distinguishing among components of a given class, particularly when they are in low abundance. For this analysis, we rely on the frequency of occurrence of a given component among best solutions. For example, at station F7 (Table 3) all 14 of the best solutions use MB-HT but none uses MB-OG or MBVLT. Thus the model unambiguously identifies the marebasalt component of the soil as high-Ti basalt. In contrast, the AN-GrF $(M=8)$ and AN-GrM $(M=7)$ components occur in subequal frequency among best solutions. Because of their compositional similarity, the model is unable to recognize that the AN component of the soil is dominated (5:1) by AN-GrF, despite the high total abundance of AN components (60\%). For the same reasons, the model is unable to identify the specific IE component. For convenience in the discussion below and in Figures 4-7, if the frequency of abundance of one component, $M_{j}$, (c.g., Table 3 ) among best solutions is two or more times that of the next most frequently used component, ${ }^{-}{ }_{k}$, of the same class (i.e., $M_{j} / M_{k} \geq 2$ ), we take this as a "distinct" model preference. If $2>M_{j} / M_{k} \geq 1.5$, that is taken as a "slight" preference; all other cases are interpreted as "no preference." Also taken as no preference are all cases where $M_{j}-M_{k}=1$ even if $M_{j} / M_{k} \geq 1.5$ (i.e., $M_{j} / M_{k}=3 / 2$, $2 / 1$, or $1 / 0)$.

5.3.2.1. AN components: At 35 stations, the two AN components together account for $50 \%$ or more of the mass of the soil (Figures 2b, 4). For 29 of these stations, one AN component is more abundant than the other by at least 2 to 1 (not shown in Figure 4). In only nine of these 29 cases does the set of best solutions distinctly favor the correct component, and there is a slight preference in one other case. In eight cases the model distinctly favors the wrong component, and for the remaining 11 cases, neither component is favored. In the worst case, at station $\mathrm{A6}$, which consists entirely of $\mathrm{AN}$ components in the ratio $80 \% \mathrm{AN}-\mathrm{GrF}$ to $20 \% \mathrm{AN}-\mathrm{GrM}$, all 33 best solutions use the AN-GrM component, but only six use (in addition) the $\mathrm{AN}-\mathrm{GrF}$ component (average abundance $23 \%$ ). Thus, because of the low concentrations of $\mathrm{Fe}$ and $\mathrm{Mg}$ in anorthositic soil and the large relative uncertainty in determination of $\mathrm{Mg}$ concentrations (Table 1), the $\alpha-p-x$ instrument is unlikely to distinguish reliably soils consisting of ferroan anorthositic materials from those consisting of magnesian anorthositic materials, even if they occur in $>50 \%$ abundance.

5.3.2.2. MG components: The highest abundance of magnesian plutonic components among the simulated soils occurs in rows 0 and 1 (Fig. 2b), with 14 samples containing $20 \%$ or $30 \% \mathrm{MG}$ components; at all 14 of these stations the main component is IE-NB (60-70\%). For six of these 14 stations, the model distinctly or slightly favors the correct (predominant) MG component; for four other stations, the model is ambiguous in that the main MG component is one of three used nearly equally by the model (Figure 5). Thus if MG components occur at $20-30 \%$ abundance levels in soils dominated by highland material (which is a greater proportion than observed in any Apollo 17 soil), there is only about a $50 \%$ chance that the specific type of MG component would be correctly identified. The model is successful in that the MG-Dun component, which was not included as a component of any of the simulated mixtures, was also not predicted to be a significant component at any station (Figure 5). In contrast, the most serious problem is the one noted earlier, that the model often indicates a significant abundance of $M G$ components in soils in which they do not occur. Also, the AN-GrM component is sometimes mistaken for MG-TrA, and MG-GaN is identified erroneously at some grid stations.

5.3.2.3. IE components: Sixty-nine of the stations contain IE components. Thirty contain a total of $50 \%$ or more and, in each of these cases, one of the two IE components dominates in abundance by at least 2 to 1 (Figure 6). The model correctly chooses the dominant component at 26 of the 30 stations, chooses the incorrect component at two, and has no preference at two. Thus when the abundance of noritic impact-melt breccia or KREEP basalt is $>50 \%$, it is usually possible distinguish between them. At 26 stations, the soil consists only of $10 \%$ or $20 \%$ of one of the two IE components. The model chooses the correct component at three stations, the incorrect component at two, and has no preference at 21 . Thus at low abundance, KREEP basalt cannot be distinguished from noritic melt breccia.

5.3.2.4. MB components: We consider first only those stations for which one of the three mare-basalt components dominates in abundance over the sum of the other two by at least 2 to 1 . Of the 49 stations meeting this criterion, 37 have at least $30 \%$ total MB components (Figure 7). Of this subset, the model identifies the correct component at 29 stations, an incorrect component at none, and has no preference at 8 . Among those stations where no preference was shown is station J4, which is a 10:90 mixture of HT:VLT. Thus the main mare-basalt component is identified correctly most of the time when mare material is abundant, but in some cases the model has no preference when one component clearly predominates.

Among the seven stations that contain subequal proportions of two or three $\mathrm{MB}$ components, the model is successful in that for only one (H9) is a component favored that is not the main component of the mixture. Of the 12 stations that have 


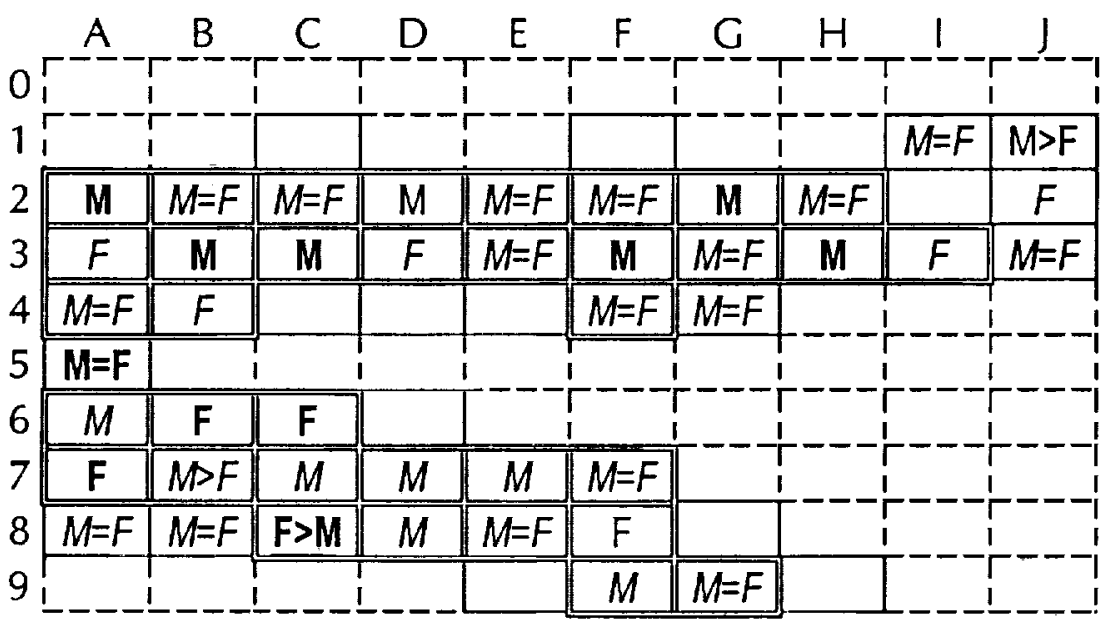

Figure 4. Semiquantitative model results of simulation $1 \mathrm{~A}$ for anorthositic norite (AN) components. Grid stations enclosed entirely by double lines contain at least $50 \%$ total AN component; those enclosed by solid single lines or a combination of solid lines and double lines contain at least $30 \%$. Others (dashed lines) contain $0 \%$ or $10 \%$. Grid stations containing letters are those for which the actual abundance of AN components totals at least $50 \%$ or the model-predicted abundance totals at least $30 \%(<30 \%$ for predicted for others; see Figure 3a1). The letter $M$ indicates that the model preferred the AN-GrM (magnesian granulite) component (by 2:1 or better) and F indicates that the model preferred the AN-GrF (ferroan granulite) component. Equal signs indicate the two components were chosen approximately equally and greater-than signs indicate that the preference was at least $3: 2$ but not as great as $2: 1$. Bold-faced letters occur where the model preference correctly represents the actual distribution. Italicized letters indicate that the model preference is incorrect or that model results are ambivalent when a clear dominance ( $\geq 2$ to 1 ) of one component over the other actually occurs. Normal type indicates that while not correct, the model choice is not grossly incorrect.

only $10 \%$ or $20 \%$ mare material (a single $\mathrm{MB}$ component at each), the model identifies the correct component five times, an incorrect component four times, and favors no component three times. For each of the four misidentifications, MB-HT was mistaken for MB-OG or MB-VLT. Thus, as before, a specific mare-basalt-like component is unlikely to be identified if its abundance is $<20 \%$.

5.3.2.5. Summary: The ability to distinguish among different components of a given class is poor for the AN compo- nents, intermediate for $\mathrm{MG}$ and IE components, and reasonably good for $\mathrm{MB}$ components. For $\mathrm{MG}, \mathrm{IE}$, and $\mathrm{MB}$ components occurring at $>50 \%$ abundance, the correct identification would be made most of the time.

5.3.3. By geography. We now show the advantage of analyzing a large number of samples systematically. Because our simulation is based on sampling on a grid, some of the ambiguous model results discussed above can be resolved by correlation of results among adjacent sampling stations. For

\begin{tabular}{|c|c|c|c|c|c|c|c|c|c|c|}
\hline & A & B & C & $\mathrm{D}$ & $E$ & $F$ & $\mathrm{G}$ & $\mathrm{H}$ & I & $\mathrm{J}$ \\
\hline 0 & $T$ & $T A=T=G N$ & $T>T A$ & $\mathrm{~T}$ & $T A=T=G N$ & $T>T A$ & $\mathbf{N}$ & $T A=T=N$ & $T A=T=N$ & $\mathrm{GN}$ \\
\hline 1 & TA & $\overline{\mathrm{TA}}$ & $T A$ & $T A$ & TA & $G N$ & $T>T A$ & & & $T>T A$ \\
\hline 2 & & & & $T A$ & $T A$ & $T A$ & $T A$ & & GN & $N>G N$ \\
\hline & & GN & & & GN & $\underline{G N}$ & & & & \\
\hline & & & & & & & & & & \\
\hline & & & & & & & & & & \\
\hline & & & & & & & & & & \\
\hline & & & & & & & & & & \\
\hline & & & & & $N$ & & & & & \\
\hline & & & $N$ & & GN & $T=T A$ & & & & \\
\hline
\end{tabular}

Figure 5. Semiquantitative model results of simulation $1 \mathrm{~A}$ for magnesian plutonic (MG) components. Grid stations enclosed entirely by double lines contain $20 \%$ or $30 \%$ total MG component; those enclosed by solid single lines or a combination of solid and double lines contain 10\%. Others (dashed lines) contain 0\%. Grid stations containing letters are those for which the actual abundance or the model-predicted abundance of MG components totals at least $20 \%(<20 \%$ for predicted for others). TA, T, N, and GN indicate, respectively, that the model preferred (by $2: 1$ or better) the MG-TrA (troctolitic anorthosite), MG-Tr (troctolite), MG-Nor (norite), or MG-GaN (gabbronorite) components. See Figure 4 for key to remaining symbols. 


\begin{tabular}{|c|c|c|c|c|c|c|c|c|c|c|}
\hline & A & B & C & D & $E$ & $F$ & $\mathrm{G}$ & $\mathrm{H}$ & 1 & $\mathrm{~J}$ \\
\hline 0[ & $\overline{\overline{\mathbf{N}}}$ & $\overline{\bar{N}}$ & $\mathbf{N}$ & K & $\mathbf{N}$ & $\mathbf{N}$ & $\mathbf{N}$ & $\mathbf{N}$ & $\mathbf{N}$ & $\mathbf{N}$ \\
\hline 1 & $\overline{\mathbf{N}}$ & $\mathbf{N}$ & $\mathbf{N}$ & $N>K$ & $N$ & $N$ & $K$ & $\mathbf{N}$ & $\mathbf{N}$ & $\mathbf{N}$ \\
\hline 2 & $\mathbf{N}$ & $\mathbf{N}$ & $\mathbf{N}$ & $\overline{\mathbf{N}}$ & $\mathbf{N}$ & $\overline{\mathbf{N}}$ & $\mathbf{N}$ & $\mathbf{N}$ & & $K$ \\
\hline 3 & & & & & & & & & & \\
\hline $4 i$ & & & $\mathbf{N}$ & & & & & & & \\
\hline $5 i$ & & & & & & & & & & \\
\hline $6 i$ & & & 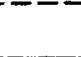 & & & $K$ & & & & \\
\hline 7 & $K$ & & $\mathbf{N}$ & & & & & & & \\
\hline $8 \pi$ & $\mathrm{K}$ & $K$ & $N=K$ & $K$ & & & & & & \\
\hline 9 & K & K & $\mathrm{N}=\mathrm{K}$ & $\mathbf{N}$ & $\mathbf{N}$ & $\mathbf{N}$ & $N=K$ & & & \\
\hline
\end{tabular}

Figure 6. Semiquantitative model results of simulation $1 \mathrm{~A}$ for incompatible element (IE) rich components. Grid stations enclosed by double lines contain at least $50 \%$ total IE component; those enclosed by a solid single line or a combination of solid and double lines contain at least $20 \%$. Others (dashed lines) contain $0 \%$ or $10 \%$. Grid stations containing letters are those for which the model predicted a total of at least $20 \%$ IE component ( $<20 \%$ for predicted for others). The letter $\mathrm{N}$ indicates that the model preferred the IE-NB (noritic impact-melt breccia) component (by $2: 1$ or better) and $\mathrm{K}$ indicates that the model preferred the IE-KR (KREEP basalt) component. See Figure 4 for key to remaining symbols.

example, the high abundances of orange glass component (Figure 7) and KREEP basalt component (Figure 6) in certain areas of the site are clearly evident in the model results, as are the mare-highlands boundaries. Even despite the poor ability to distinguish among certain components for individual samples, there is a distinct hint of a concentration of troctolitic material in the northwest comer of the site (Figure 5) and ferroan anorthositic-norite material at the western portion of the traverse area at the bottom of the South Massif (Figure 4; stations $\mathrm{A} 7, \mathrm{~B} 6$, and $\mathrm{C} 6$ ). In a real mission, results such as these for soils would provide a focus for the selection of rock samples for analysis. Even for a linear traverse, we would expect, based on our Apollo experience, that for soil samples analyzed every kilometer (for example), adjacent samples would be similar in composition because they are composed of the same components, but in slightly different proportions. Only for soils in or near fresh craters or unusual topographic or geographic features would we expect large compositional differences to occur over short distances.

The correlation of regolith composition with geography [e.g., Rhodes et al., 1974] is in large part the basis of our argument that, given a finite amount of analysis time during a rover mission, numerous $(\sim 100)$ low-precision $(\sim 1$ hour $)$ analyses of soils will provide more geological information than a few $(\sim 10)$ high-precision $(\sim 10$ hour) analyses. Clearly, however, analysis times can be too short to provide any useful information (e.g., 1000 analyses of 0.1 hour each), so determination of the optimum number of analyses is an important

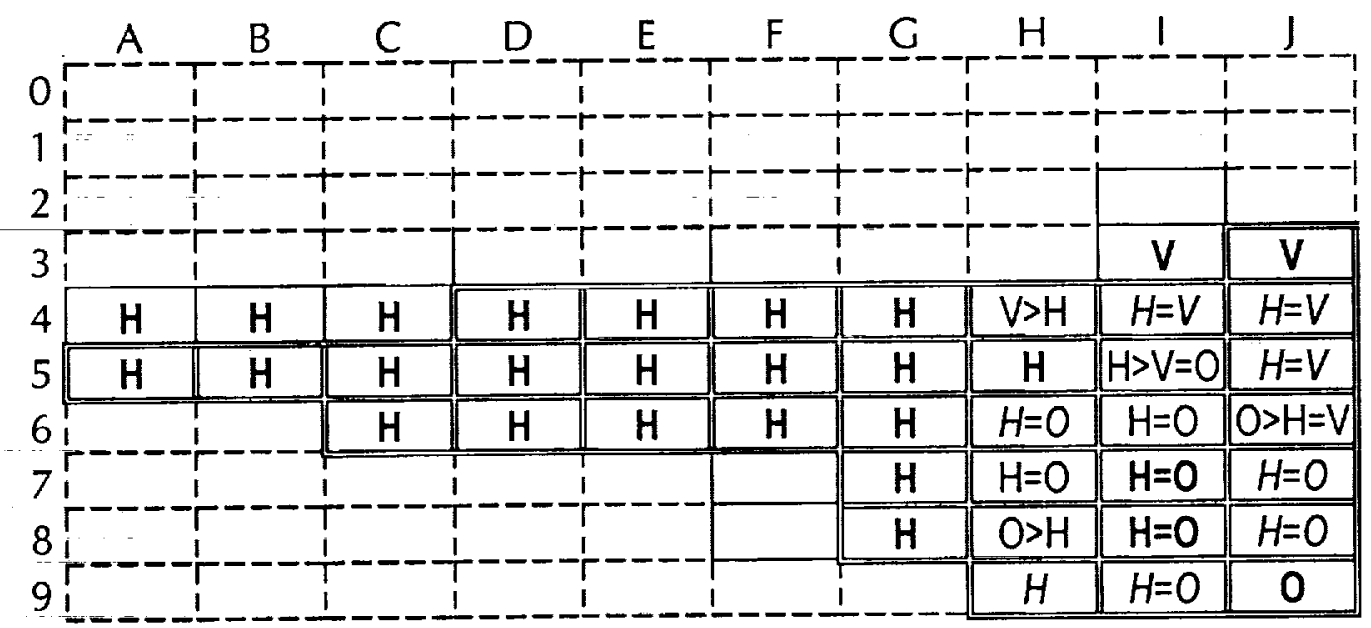

Figure 7. Semiquantitative model results of simulation $1 \mathrm{~A}$ for mare basalt $(\mathrm{MB})$ components. Grid stations enclosed entirely by double lines contain at least $50 \%$ total $\mathrm{MB}$ component; those enclosed by a solid single line or a combination of solid and double lines contain $30 \%$ or $40 \%$. Others (dashed lines) contain $0 \%$, $10 \%$, or $20 \%$. Grid stations containing letters are those for which the model predicted a total of at least $30 \% \mathrm{MB}$ component ( $<30 \%$ for predicted for others). $\mathrm{H}, \mathrm{V}$, or $\mathrm{O}$ indicate, respectively, that the model preferred (by $2: 1$ or better) the MB-HTi (high-Ti basalt), MB-VLT (very low Ti basalt), or MB-OG (orange glass) component. See Figure 4 for key to remaining symbols. 
design specification of any mission. For example, it may be most effective to use variable analysis times and analyze until some predetermined precision (e.g., 20\%) for some key element (e.g., $\mathrm{Mg}$ ) is obtained or do longer-duration analyses only when it appears that some major change in composition has occurred. Because soils sampled a kilometer apart are usually similar in composition, analytical precision and thus model reliability could also be improved for a traverse (linear or grid) by modeling a sliding average of analytical results obtained from adjacent sampling stations.

\subsection{Summary of Simulation $1 \mathrm{~A}$}

In this idealized simulation, soil compositions are calculated as mixtures of a small number of components of fixed composition, and simulated analyses are generated by degrading those soil compositions according to the expected precision of the $\alpha-p-x$ spectrometer. One incompatible element is determined with $1-\sigma$ relative precision of $\pm 25 \%$. On average, the identity and proportion of the components of the simulated compositions can be determined reasonably well by class of component using a mixing-model technique to resolve the mixtures into constituent components. There is a tendency for the model to slightly overestimate or underestimate systematically the abundance of some classes of components (abundances of $\mathrm{Mg}$-rich plutonic components are overestimated and those of components rich in incompatible elements are underestimated). $\mathrm{Mg}$-rich components are often predicted to occur in soils that contain no such component. For major components of the mixture, the specific component of a class is usually identified correctly (e.g., high-Ti basalt or orange glass), but for minor components, identifications are usually ambiguous or incorrect. It is not possible to distinguish between low- $\mathrm{Mg} / \mathrm{Fe}$ and high- $\mathrm{Mg} / \mathrm{Fe}$ feldspathic components unless they are at very high abundance. The good results of the model depend strongly on our precise knowledge of the compositions of the components. If these compositions had significant systematic errors in one or more elements, additional ambiguities would occur in the model results. Ambiguities associated with imprecise analyses can be resolved by comparing results among samples taken in the same vicinity.

We have also used the mixing model approach on simulated analyses based on actual Apollo 17 soil compositions instead of idealized mixtures. In these tests, the model results tend to be somewhat more ambiguous with respect to identifying the actual major lithologies of a soil than with the ideal mixtures of simulation $1 \mathrm{~A}$. We attribute this to the larger number of components in an actual soil and the natural variation in composition of any nominal component.

We stress that the presence in a soil of even a small amount of a lithology that is not represented by a component of the model can produce unrealistic model results. For example, at Apollo 17 the orange glass (MB-OG) is a compositionally distinct lithology and an important component of the regolith, but one that is not represented by a "rock," except for a few orange-glass clods and breccias. If, in our simulated mission, the deposit of orange glass that occurred in the southeast corner of the site was not recognized as a concentration of pyroclastic ash and, consequently, no component representing the orange glass was included in the model, the model results for many soils would be unrealistic and misleading. Because the MB-OG component is considerably more magnesian than the MB-HT component (Table 1), the model would compensate for the lack of an MB-OG component by including greater abundances of MB-HT and MG components. At the extreme, the actual composition of the orange-glass soil of station 4 at Apollo 17 is itself best modeled (as in preliminary test 2) as a mixture of $75 \% \mathrm{MB}-\mathrm{HT}$ and $25 \%$ MG-Dun components, when the MB-OG component is not included in the model. The poor fit $\left(\chi^{2} / v=2.9\right)$ might suggest the presence of a "missing component," but if the model were based on a single imprecise analysis (as in simulation 1A), the actual model results would be unpredictable and unfailingly misleading.

\section{Simulation 1B: No Incompatible Elements Are Determined}

For simulation $1 \mathrm{~B}$, we have repeated the model calculations of simulation $1 \mathrm{~A}$ but have eliminated Th concentrations as a constraint in order to test the success of interpreting data if no instrument is available to determine concentrations of incompatible elements. Predictably, the model is unable to distinguish between IE and MG components. For example, in row 0 all samples contain $70 \%$ IE-NB; without $\mathrm{Th}$, the modelpredicted abundance of IE components is $20 \pm 15 \%$ (mean \pm standard deviation) (Figure 8). Similarly, the modelpredicted abundance of $M G$ components is $67 \pm 16 \%$, compared with an actual abundance of $30 \%$. As noted above, when Th is included, the tendency is to overestimate MG components at the expense of IE components; without Th (or some other incompatible element), the tendency is the same, but to a much greater and unacceptable magnitude. Without Th, the precision for the total abundance of $\mathrm{MB}$ components also degrades. For 23 stations, the difference between the actual and model abundance of $\mathrm{MB}$ components exceeds $10 \%$ in simulation $1 \mathrm{~B}$, compared to only seven stations in simulation 1A. There is also a greater tendency for the model to indicate the presence of $\mathrm{MB}$ components at stations at which they do not occur. There is little effect, however, on the predicted abundance of AN components, presumably because the abundance of $\mathrm{AN}$ components is constrained primarily by the Al concentration, which is determined well by the $\alpha-p-x$ spectrometer.

Overall, the inability to determine the concentration of at least one incompatible element would severely hamper our ability to interpret data for the major elements in a geologically useful way in regions with a significant KREEP component (Figure 8), such as the Apollo sites. In contrast, the ability to determine an incompatible element precisely would be of little benefit for a rover mission to a region with only a minor abundance of KREEP-bearing lithologies (most of the Moon's surface), such as the source regions of the feldspathic lunar meteorites (e.g., ALHA81005, Yamato-86032).

\section{Simulation 2: Identification of Pyroclastics}

One possible goal of a rover mission to the Moon would be the study of pyroclastic ash deposits, "Dark-mantle" deposits (believed to be pyroclastic in origin) have been identified remotely at numerous locations [Head, 1976] and the direct study of such deposits should greatly improve our understanding of the generation, transport, and eruption of lunar mare lavas. At Apollo 17, a deposit of nearly pure pyroclastic ash (orange glass) was discovered at station 4; however, lesser amounts of ash were found in soils of all other stations. It is possible that the location of an ash deposit, or even a volcanic 


\section{(a) Actual \% IE components}

\begin{tabular}{l|rrrrrrrrrr|}
\multicolumn{1}{l}{} & $\mathrm{A}$ & $\mathrm{B}$ & $\mathrm{C}$ & $\mathrm{D}$ & $\mathrm{E}$ & $\mathrm{F}$ & $\mathrm{G}$ & $\mathrm{H}$ & $\mathrm{I}$ & $\mathrm{J}$ \\
\cline { 2 - 10 } & 70 & 70 & 70 & 70 & 70 & 70 & 70 & 70 & 70 & 70 \\
1 & 60 & 60 & 60 & 60 & 70 & 60 & 60 & 70 & 60 & 50 \\
2 & 30 & 40 & 50 & 40 & 40 & 30 & 40 & 40 & 30 & 30 \\
3 & 20 & 10 & 10 & 10 & 10 & 20 & 20 & 10 & 10 & 10 \\
4 & & 10 & 20 & 20 & & 10 & & & & \\
5 & & & 10 & & 10 & 20 & 10 & & & \\
6 & & & & & & 20 & & & & \\
7 & 30 & 20 & 20 & 20 & 10 & 10 & & & \\
8 & 70 & 60 & 50 & 30 & 20 & 10 & & & & \\
9 & 100 & 100 & 100 & 100 & 70 & 50 & 20 & 10 & & \\
\cline { 2 - 9 }
\end{tabular}

(b) Simulation $1 \mathrm{~A}$ : with $\mathrm{Th}$

\begin{tabular}{l|rrrrrrrrrr|}
0 & 61 & 77 & 59 & 42 & 84 & 69 & 61 & 78 & 87 & 72 \\
1 & 56 & 53 & 47 & 29 & 62 & 26 & 40 & 58 & 40 & 44 \\
2 & 32 & 37 & 55 & 36 & 32 & 34 & 53 & 33 & 14 & 26 \\
3 & 10 & 2 & 3 & 3 & 15 & 8 & 16 & 2 & 2 & 12 \\
4 & & 2 & 8 & 33 & & & & 2 & & \\
5 & 2 & & 7 & & 6 & 11 & 5 & & & \\
6 & & 3 & 1 & & & 21 & & 1 & & \\
7 & 35 & 18 & 24 & 5 & 5 & 2 & & & \\
8 & 66 & 53 & 38 & 25 & 10 & 2 & & & \\
9 & 97 & 89 & 39 & 94 & 58 & 33 & 33 & 4 & & \\
\hline
\end{tabular}

(c) Simulation 1B: without Th

\begin{tabular}{rrrrrrrrrrr|}
0 & 24 & 26 & 14 & & 17 & 14 & 8 & 16 & 57 & 20 \\
1 & 0 & 17 & 20 & 5 & 13 & 13 & 36 & 46 & 23 & 32 \\
2 & 4 & 14 & & & 11 & 7 & 21 & & 7 & 40 \\
3 & & & 7 & 15 & 6 & & & 12 & 27 & 26 \\
4 & 21 & & & & & & & 36 & & \\
5 & 2 & & 3 & & & 2 & 7 & 3 & & 8 \\
6 & 1 & 7 & 6 & 8 & 9 & 5 & 2 & 3 & & 5 \\
7 & 18 & 9 & 19 & & & & 9 & 6 & & 3 \\
8 & & 24 & 10 & 3 & 24 & & 3 & 11 & 5 & \\
9 & 79 & 51 & 8 & 50 & 34 & 11 & 17 & 19 & & \\
\hline
\end{tabular}

Figure 8. Comparison of (a) actual percentage of IE components (noritic impact-melt breccia plus KREEP basalt; same as Figure $2 \mathrm{~b}$ ) with (b) model results for simulation $1 \mathrm{~A}$ in which Th concentrations were obtained and (c) model results for simulation $1 \mathrm{~B}$ in which Th concentrations were not obtained. Model results for simulation lA would be essentially similar for any incompatible element determined with the same precision (25\%).

vent, could be discovered by guiding the rover in the direction of increasing concentration of pyroclastic ash in the regolith.

In order to assess the success of determining the abundance of pyroclastic ash when it occurs in a regolith consisting largely of comminuted basalt, we have devised the following test: In simulation $2 \mathrm{~A}$, we calculated compositions of binary mixtures of the MB-OG and MB-HT components at $10 \%$ increments. We then generated a set of five simulated analyses for each true composition (instead of one, as in simulation 1A), yielding a total of 55 simulated analyses (including the end-member compositions corresponding to $100 \% \mathrm{MB}-$ OG and $100 \% \mathrm{MB}-\mathrm{HT}$ ). Other conditions were similar to those of simulation 1A. Among all best solutions for each analysis, we calculated the simple average of the fraction of MB-OG component predicted by the model (Figure 9a). In order to test the effect of mixtures containing some highland material, in simulation 2B (Figure 9b) we also tested tertiary mixtures each consisting of $10 \%$ highlands material (Apollo 17 station 2 soil) and incremental mixtures of MB-OG and MB-HT (i.e., 10:90:0, 10:80:20 .., and 10:0:90).

On average, the model is successful at identifying the presence of the OG component in mixtures of high-Ti basalt and orange glass and estimating the abundance of the OG compo-
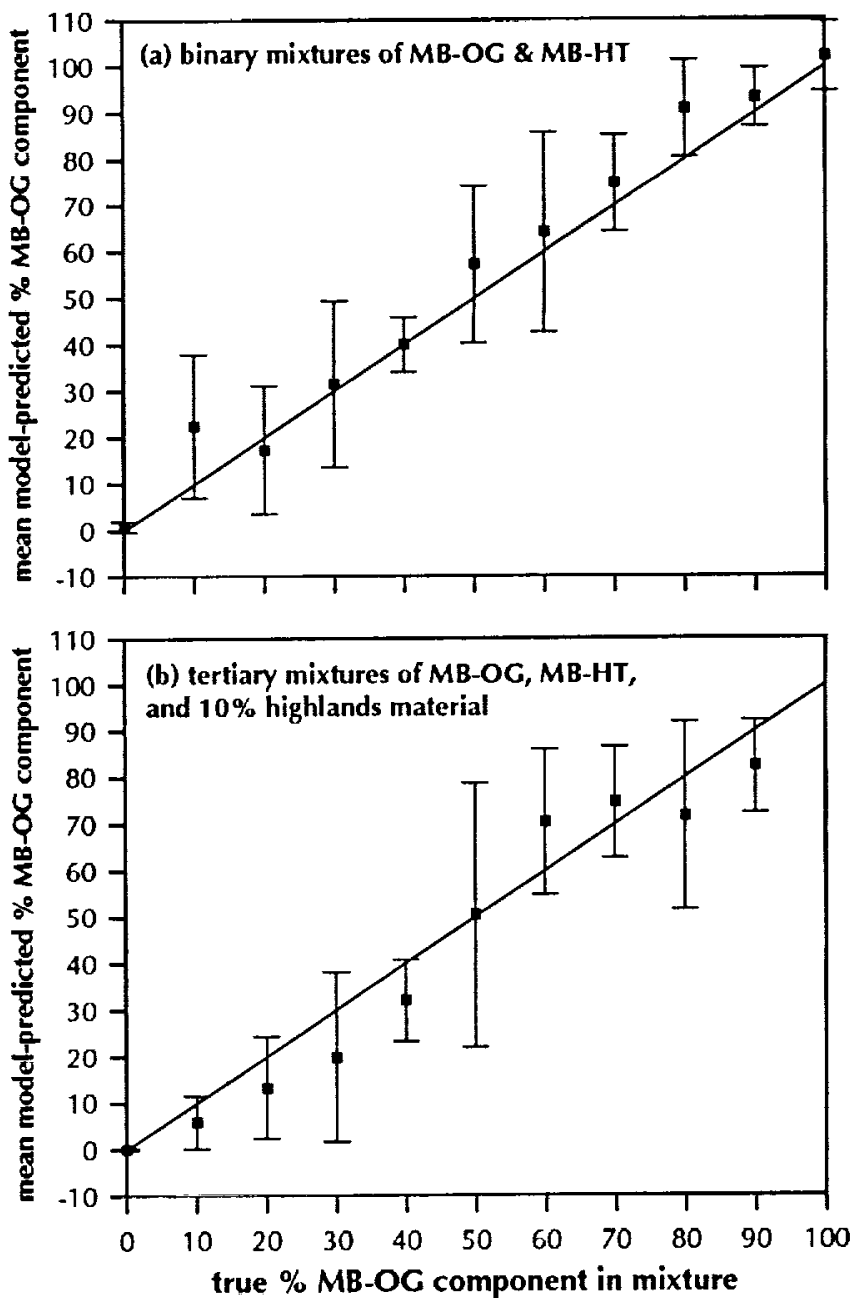

Figure 9. Results of simulation 2: Comparison of abundance of MB-OG (orange glass) component predicted by the mixing model on simulated analyses of ideal mixtures with the actual abundance of MB-OG in the mixture. Each point represents the mean results for five 1-hour analyses; the error bars represent the sample standard deviation $(N=5)$. For reference, the diagonal lines represent perfect agreement between actual and model-predicted abundances. (a) Simulation 2A: binary mixtures of MB-OG and MB-HT (high Ti mare basalt) components. (b) Simulation 2B: tertiary mixtures of MB-OG, MB$\mathrm{HT}$, and $10 \%$ highlands material. 
nent. (In a real rover mission, it would be difficult to take advantage of this capability unless or until a deposit of nearly pure pyroclastic ash was encountered, as it was at Apollo 17, because for modeling, the composition of the pure ash is needed.) However, in many cases the model-predicted abundance based on a single analysis is poor. For example, the standard deviation in the absolute value of the differences between the true percent $O G$ component and the modelpredicted percent $O G$ component is $8 \%$ for simulation $2 \mathrm{~A}$ and $10 \%$ for simulation $2 \mathrm{~B}$. For about $15 \%$ of the samples, the difference exceeds $20 \%$ (e.g., the true fraction is $50 \%$ and the model predicted fraction is $>70 \%$ or $<30 \%$ ). The absolute uncertainty in $f_{O G}$ is not a function of the magnitude of $f_{O G}$ (Figure 9).

\section{Conclusions}

Our simulations show that if a geochemical rover equipped with the $\alpha-\mathrm{p}-\mathrm{x}$ spectrometer of Economou and Turkevich [1992] and the ability to measure well the concentration of at least one incompatible element were sent back to Apollo 17 site, and if analyses of short duration of numerous ( 100) soil samples were obtained, much of what we have determined from the retumed soil samples about the distribution of subsurface rock types and site geology could be learned. This success requires either (1) our present knowledge, based on laboratory analysis of Apollo 17 rocks, of the composition of the prevalent rock types that constitute the regolith or (2) highprecision analyses of those same rock types obtained by the rover in the field. The rover data would be sufficient to allow us to estimate well the relative proportions of highland and mare material in the regolith. Specific lithologic components of the soil that occur in high abundance are likely to be identified unambiguously, and their relative abundances determined. Components that occur in low abundance $(<20 \%)$ are not likely to be identified correctly, but their generic class of material (basalt, KREEP-bearing highlands, anorthositic highlands) is likely to be inferred. Our confidence in identifying components of the regolith is strengthened by analyzing several samples in near proximity and obtaining consistent results. (Additional conclusions are discussed in the summary sections, above.)

Our results can be extrapolated to indicate that certain types of rocks should easily be identified and distinguished from other similar types of rocks. For example, if a rock of troctolitic, KREEP basaltic, or VLT basaltic composition was encountered, it is likely that it would be identified or, at least, recognized as unusual on the basis of composition. Clearly, other instruments and imaging equipment on board the rover that could determine features such as mineralogy, morphology, grain size, texture, color, and fracture would be useful for confirming the identification or resolving ambiguities based on chemical composition. These conclusions require, however, that the instruments be able to examine interior portions of rocks. Recent work by $M c K a y$ et al. [1995] shows that patinas caused by space weathering can have significantly different compositions than bulk samples; it is not yet known how serious this effect is for soils.

However, without the ability to measure an incompatible element ( $\mathrm{K}, \mathrm{P}, \mathrm{Zr}, \mathrm{Ce}, \mathrm{Th}$, etc.) when those elements occur in high concentration, the mission would be much less successful, as we could not reliably distinguish among components of KREEP-bearing impact-melt breccias, KREEP basalt, and mafic plutonic rocks. Even if other instruments could be used in conjunction with the $\alpha-p-x$ instrument to distinguish, for example, a sample of impact-melt breccia from that of a plutonic norite, the relative proportions of these two lithologies in the regolith could not be reliably determined without the ability to determine concentrations an incompatible element.

We conclude that a rover mission equipped with an $\alpha-p-x$ spectrometer could usefully expand our understanding of the geology of the Taurus-Littrow site and adjacent areas that were part of the rover traverse. Interpretations would be less ambiguous and more detailed if an incompatible element could be determined, and if other instruments provided information complementary to chemical compositions. We cannot fail to note that the quality of the results of such a mission falls far short of that obtainable from retumed samples, not to mention the richness of other information that direct laboratory studies provide. This contrast would be heightened if the rover were sent to a new lunar site, where the nature of the materials contributing to the regolith could not be established with the same precision or thoroughness as we have for the Apollo 17 site. This imprecision and ambiguity are not merely a lunar problem. Interpretations will be even more speculative for data from Mars, some asteroids, etc., where we have not already characterized the variety of regolith materials and the processes that have produced them.

Thus this work stands as support for rover traverses for measurement of chemical composition, but as stronger support in favor of sample returns.

Acknowledgments. This work was supported by the National Aeronautics and Space Administration through grant NAGW-3343. We appreciate the helpful criticisms of W. V. Boynton and an unidentified reviewer knowledgeable in the $\alpha-p-x$ instrument.

\section{References}

Abramowitz, M., and I. Stegun (Eds.), Handbook of Mathematical Functions with Formulas, Graphs, and Mathematical Tables, 1046 pp., John Wiley, New York, 1972.

Blewitt, D. T., B. R. Hawke, P. G. Lucey, and P. D. Spudis, A spectral survey of the Crisium region of the Moon (abstract), Lunar Planet. Sci. , XXV, 127-128, 1994.

Blanchard, D. P., L. A. Haskin, J. W. Jacobs, J. C. Brannon, and R. L. Korotev, Major and trace element chemistry of boulder 1 at station 2, Apollo 17, Moon, 14, 359-371, 1975.

Boynton, W. V., P. A. Baedecker, C.-L. Chou, K. L. Robinson, and J. T. Wasson, Mixing and transport of lunar surface materials: Evidence obtained by the determination of lithophile, siderophile, and volatile elements, Proc. Lunar Sci. Conf., 6th, 2241-2259, 1975.

Clark, B. C., A. K. Baird, R. J. Weldon, D. M. Tsusaki, L. Schnabel, and M. P. Candelaria, Chemical composition of Martian fines, $J$. Geophys. Res., 87, 10,059-10,067, 1982.

Delano, J. W., Pristine lunar glasses: Criteria, data, and implications, Proc. Lunar Planet. Sci. Conf., 16th, Part 2, J. Geophys. Res., 9I, suppl., D201-D213, 1986.

Economou, T. E., and A. L. Turkevich, An alpha particle instrument with alpha, proton, and X-ray modes for planetary chemical analysis, Nucl. Instrum. Methods, 134, 391-400, 1976.

Economou, T. E., and A. L. Turkevich, An $\alpha-p-x$ analytical instrument for lunar resource investigations, Joint Workshop on New Technologies for Lunar Resource Assessment, LPI Tech. Rep. $92-06,20-22,1992$.

Haskin, L. A., and P. H. Warren, Lunar chemistry, in Lunar Sourcebook, chap. 8, edited by G. Heiken, D. Vaniman, and B. M. French, pp. 357-474, Cambridge Univ. Press, New York, 1991. 
Head, J. W., Lunar volcanism in space and time, Rev. Geophys., 14, $265-300,1976$.

Heiken, G., and D. S. McKay, Petrography of Apollo 17 soils, Proc. Lunar Sci. Conf., Sth, 843-860, 1974.

Jolliff, B. L., K. M. Rockow, R. L. Korotev, and L. A. Haskin, Sampling the Apollo 17 highlands using soils and lithic fragments (abstract), Lunar Planet. Sci., XXV, 637-638, 1994.

Jolliff, B. L., R. L. Korotev, K. M. Rockow, and L. A. Haskin, Apollo 17 impact-melt breccias: In search of Imbrium components (abstract), Lunar Planet. Sci., XXVI, 691-692, 1995.

Korotev, R. L., and D. T. Kremser, Compositional variations in Apollo 17 soils and their relationship to the geology of the Taurus-Littrow site, Proc. Lunar Planet. Sci, 22, 275-301, 1992.

Laul, J. C., J. J. Papike, and S. B. Simon, The lunar regolith: Comparative studies of the Apollo and Luna sites, Chemistry of soils from Apollo 17, Luna 16,20, and 24, Proc. Lunar Planet. Sci., I2B, 389-407, 1981 .

Lindstrom, D. J., and R. R. Martinez, Trace elements in small VLT basalt clasts from 72235 (abstract), Lunar Planet. Sci., XXVI, 845-846, 1995.

Lindstrom, M. M., and D. J. Lindstrom, Lunar granulites and their precursor anorthositic norites of the early lunar crust, Proc. Lunar Planet. Sci. Conf., 16!h, Part 2, J. Geophys. Res., 91, suppl., D263-D276, 1986.

McKay, D. S., S. J. Wentworth, and K. M. McBride, Patinas on lunar rocks: The unusual surface of Apollo 17 basalt 75075, paper presented at Twenty-Sixth Lunar Planet. Sci., Conference, NASA and Lunar and Planetary Institute, Houston, Texas, March 13-17, 1995.

Metzger, A. E., M. I. Etchegaray-Ramirez, and E. L. Haines, Thorium concentrations in the lunar surface: $V$. Deconvolution of the central highlands region, Proc. Lunar Planet. Sci. Conf., I2B, 751-766, 1981.

Rhodes, J. M., K. V. Rodgers, C. Shih, B. M. Bansal, L. E. Nyquist, H. Wiesmann, and N. J. Hubbard, The relationships between geology and soil chemistry at the Apollo 17 landing site, Proc. Lunar Sci. Conf., Sth, 1097-1117, 1974.

Ryder, G., and M. D. Norman, Catalog of pristine nonmare materials. part 1. non-anorthosites (rev.), 147 pp., Rep. JSC 14565, NASA Johnson Space Cent., Houston, Tex., 1979.

Salpas, P. A., L. A. Taylor, and M. M. Lindstrom, Apollo 17 KREEPy basalts: Evidence for nonuniformity of KREEP, Proc. Lumar Planet. Sci. Conf., 17th, Part 2, J. Geophys. Res., 92, suppl., E340-E348, 1987.

Spudis, P. D., The Geology of Muli-Ring Impact Basins: The Moon and Other Planets, 263 pp., Cambridge Univ. Press, New York, 1993.
Spudis, P. D., and B. R. Hawke, Chemical mixing model studies of lunar orbital geochemical data: Apollo 16 and 17 highlands compositions, Proc. Lunar Planet. Sci. Conf., 12B, 781-789, 1981.

Spudis, P. D., B. R. Hawke, and P. Lucey, Composition of Orientale basin deposits and implications for the lunar basin-forming process. Proc. Lunar Planet. Sci. Conf., 15th, Part 1, J. Geophys. Res., 89, suppl., C197-C210, 1984.

Stơmer, D., H.-D. Knöll, U. B. Marvin, C. H. Simonds, and P. H. Warren, Recommended classification and nomenclature of lunar highlands rocks-a committee report, in Proc. Conf. Lunar Highlands Crust, edited by J. J. Papike and R. B. Merrill, Geochim Cosmochim. Acta, suppl. 12, 51-70, 1980.

Surkov, Yu. A., L. P. Moskalyova, V. P. Kharyukova, A. D. Dudin, G. G. Smirnov, and S. Ye. Zaitseva, Venus rock composition at the Vega 2 landing site, Proc. 17th Lunar Planet. Sci. Conf., Part 1, J. Geophys. Res., 91, suppl., E215-E218, 1986.

Taylor, G. J., P. Warren, G. Ryder, J. Delano, C. Pieters, and G. Lofgren, Lunar rocks, in Lunar Sourcebook, chap. 6, edited by G. Heiken, D. Vaniman, and B. M. French, 736 pp., Cambridge Univ. Press, New York, 1991

Turkevitch, A. L., J. H. Patterson, and E. J. Franzgrote, Chemical analysis of the moon at the Surveyor 6 landing site, Science, 160, $1108-1110,1968$.

Warren, P. H., and J. T. Wasson, The origin of KREEP, Rev. Geophys., 17, 73-88, 1979a.

Warren, P. H., and J. T. Wasson, The compositional-petrographic search for pristine nonmare rocks: Third foray, Proc. Lunar Planet. Sci. Conf., 10th, 583-610, 1979b.

Warren, P. H., D. N. Shirley, and G. W. Kallemeyn, A potpourri of pristine Moon rocks, including a VHK mare basalt and a unique, augite-rich Apollo 17 anorthosite, Proc. Lunar Planet. Sci. Conf., 16th, Part 2, J. Geophys. Res., 91, suppl., D319-D330, 1986.

Wentworth, S., G. J. Taylor, R. D. Warner, K. Keil, M.-S. Ma, and R. A. Ma, The unique nature of Apollo 17 VLT basalts, Proc. Lunar Planet. Sci. Conf., 10th, 207-223, 1979.

L. A. Haskin, B. L. Jolliff, and R. L. Korotev, Washington University, Department of Earth and Planetary Sciences, Campus Box 1169, One Brookings Drive, St. Louis, MO 63130-4899. (e-mail: rlk@wuinaa.wustl.edu)

(Received November 10, 1994; revised May 26, 1995; accepted May 30, 1995.) 